\title{
Purinergic regulation of the immune system
}

\section{Caglar Cekic ${ }^{1}$ and Joel Linden ${ }^{2}$}

Abstract | Cellular stress or apoptosis triggers the release of ATP, ADP and other nucleotides into the extracellular space. Extracellular nucleotides function as autocrine and paracrine signalling molecules by activating cell-surface $\mathrm{P} 2$ purinergic receptors that elicit pro-inflammatory immune responses. Over time, extracellular nucleotides are metabolized to adenosine, leading to reduced P2 signalling and increased signalling through anti-inflammatory adenosine ( $\mathrm{P} 1$ purinergic) receptors. Here, we review how local purinergic signalling changes over time during tissue responses to injury or disease, and we discuss the potential of targeting purinergic signalling pathways for the immunotherapeutic treatment of ischaemia, organ transplantation, autoimmunity or cancer.

\section{Inotropic \\ Ligand-gated channel type \\ of receptor. \\ Metabotropic \\ $G$ protein-coupled type of \\ receptor. \\ Inflammasome \\ A multiprotein complex in \\ myeloid cells that is activated upon cellular infection or stress and triggers the maturation of pro-inflammatory cytokines.}

'Department of Molecular Biology and Genetics, Bilkent University, Ankara 06800, Turkey.

${ }^{2}$ Division of Developmental Immunology, La Jolla Institute for Allergy and Immunology, La Jolla, California 92037, USA. Correspondence to J.L. joel@lii.org

doi: 10.1038/nri.2016.4

Published online 29 Feb 2016
Purines existed in primaeval seas and had a central role in prebiotic chemical evolution and the origin of life ${ }^{1}$. Upon the emergence of cells, intracellular purines evolved to be key participants in metabolic processes, and cell surface purinergic receptors evolved to respond to purines that had escaped from damaged cells ${ }^{2-4}$. Four of these receptors became $\mathrm{G}$ protein-coupled adenosine receptors also called P1 purinergic receptors. Eighteen other P2 purinergic receptors evolved to bind ATP and/or other purine or pyrimidine nucleotides that are released from necrotic or apoptotic cells ${ }^{5}-$ six P2X purinergic receptor (P2XR) homotrimers, four P2XR heterotrimers and eight P2YR G protein-coupled receptors (GPCRs) (TABLE 1). When cells become apoptotic or are stressed by shear or changes in osmotic pressure, they release ATP through cell-surface membrane channels, principally pannexin 1 (REFS 6,7). In addition, various mechanisms have evolved to enable the controlled release of ATP, ADP and other nucleotides from intact cells. These include the release of nucleotides in granules from nerve terminals ${ }^{8}$, platelets $^{9}$ and mast cells ${ }^{10}$.

In this Review, we develop the idea that, following tissue injury, purinergic signalling can be divided into three temporal phases (FIG. 1). First, there is an acute phase of purinergic signalling that lasts minutes to hours, during which ATP is rapidly released into the extracellular space from damaged or stressed cells, accumulates to high levels and has chemotactic and excitatory effects on immune cells. Second, there is a subacute phase of purinergic signalling that lasts hours to days, in which there is a decrease in the extracellular ratio of ATP/ adenosine. The reduced ATP signalling and increased activation of $\mathrm{A} 2 \mathrm{~A}$ and $\mathrm{A} 2 \mathrm{~B}$ adenosine receptors (A2ARs and A2BRs, respectively) serves to limit the extent and duration of inflammation. Third, there is a chronic phase of purinergic signalling lasting days to weeks (or longer) that is associated with a low extracellular ratio of ATP/adenosine and with the initiation and progression of wound-healing processes that sometimes cause pathological tissue remodelling. In some instances, in tissues that have high cell turnover such as in chronically inflamed tumours, both extracellular ATP and adenosine may be elevated for extended periods.

ATP released from stressed, apoptotic or necrotic cells promotes rapid inflammation by binding to excitatory ATP receptors; these comprise inotropic P2XR and metabotropic P2YR subtypes that amplify T cell receptor (TCR) signalling in lymphocytes and promote inflammasome activation in macrophages and dendritic cells (DCs) $)^{11-13}$. In the extracellular space, ATP is converted to ADP and AMP by enzymes belonging to three ectonucleotidase families: namely, alkaline phosphatases, ectonucleoside triphosphate diphosphohydrolases (ENTPDases) including CD39 (also known as NTPDase 1), and ectonucleotide pyrophosphatases/ phosphodiesterases (ENPPs). NAD ${ }^{+}$and ADP-ribose, which is produced from $\mathrm{NAD}^{+}$by CD38 (also known as ADPRC1), serve as additional sources of AMP owing to the enzymatic activity of ectonucleotide pyrophosphatase/phosphodiesterase 1 (ENPP1, also known as CD203a or PC1) ${ }^{14}$. Extracellular AMP is primarily converted to adenosine by CD73 (also known as 5-NT) ${ }^{15}$. Adenosine signalling is terminated by the activity of adenosine deaminase (ADA), which converts adenosine to inosine, which is a nucleoside that weakly activates rodent, but not human, A3Rs and has little direct effect on A1Rs, A2ARs or A2BRs ${ }^{16}$. Adenosine signalling can also be terminated by cellular uptake of adenosine 


\section{Spare receptors}

Receptors that lead to an increase in the functional potency of a response to receptor occupancy by an agonist as a result of increased receptor expression

Pannexins

A family of membrane spanning proteins consisting of pannexin 1, pannexin 2 and pannexin 3. Pannexin 1 is widely expressed and oligomerizes into a hexamer to form a single membrane channel. through equilibrative nucleoside transporters (ENTs) or concentrative nucleoside transporters $(\mathrm{CNTs})^{17,18}$, as well as through adenosine phosphorylation to AMP by intracellular adenosine kinase. Following tissue injury, there is an induction of the ectoenzymes that degrade ATP, $\mathrm{ADP}$ and AMP to adenosine ${ }^{19}$. At the same time, hypoxia and damage-associated molecular patterns (DAMPs) released from injured cells trigger the upregulation of anti-inflammatory A2ARs and A2BRs on immune cells; this upregulation of spare receptors increases the potency of adenosine to limit the extent and duration of inflammation and to promote wound-healing processes. Excluded from this discussion are the many effects of purinergic signalling in non-immune cells, which include the regulation of physiological processes such as wakefulness, blood pressure, nerve growth and pain, as discussed elsewhere (see REFS 20-22).

\section{Purinergic receptors on immune cells}

Overview of P2XR and P2YR signalling in immune cells. ATP, UTP and other nucleotides can be released from apoptotic cells through pannexin 1 channels that are activated by caspase-mediated cleavage of the pannexin pore-associated carboxy-terminal autoinhibitory region ${ }^{23}$. ATP also can be released through additional cell-membrane channels, including other pannexins, connexins, maxichannels and $\mathrm{P} 2 \mathrm{X}_{7} \mathrm{R}$ pores ${ }^{22}$. As these nucleotides are chemoattractants, they have been

Table 1 | Expression and functions of purinergic receptors on cells of the immune system

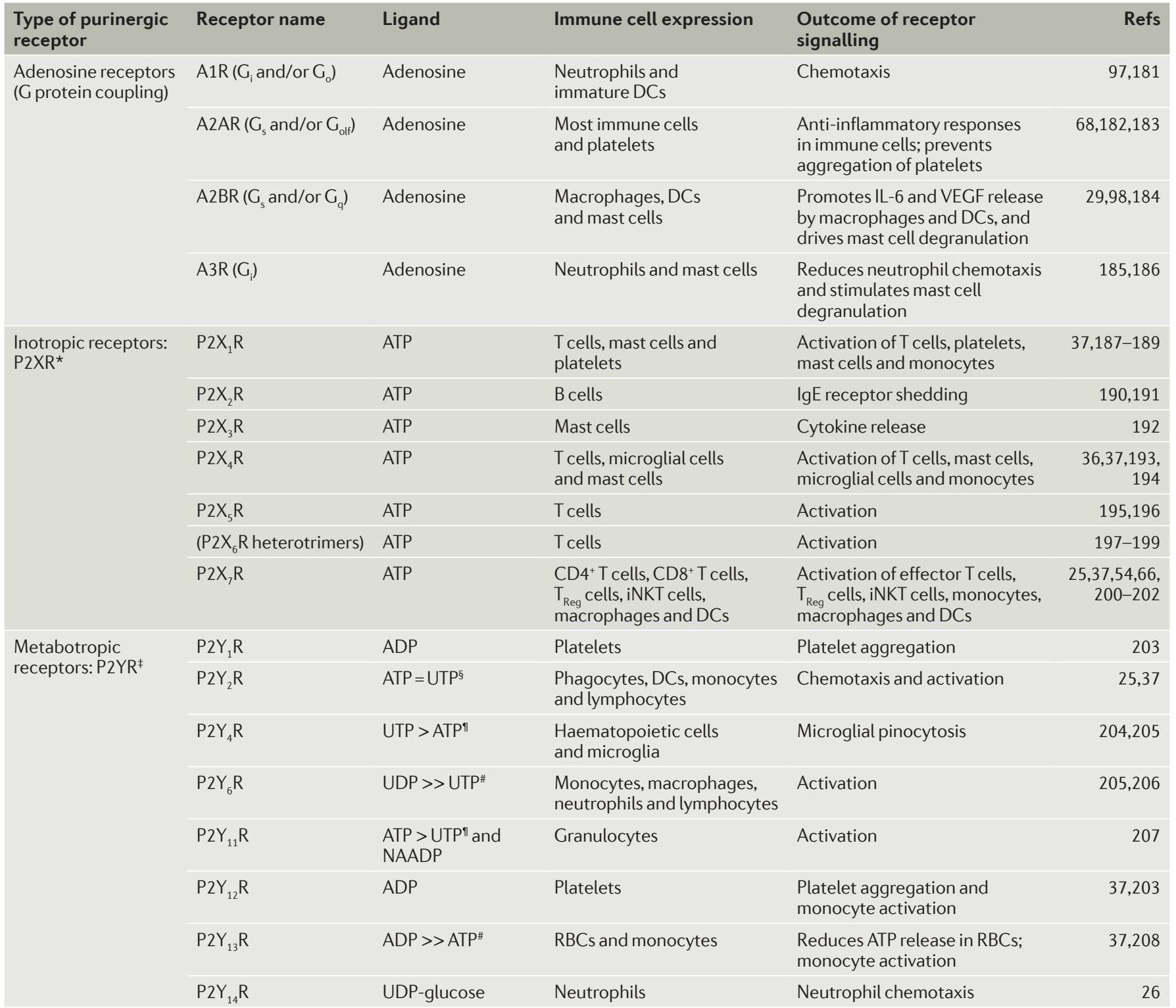

DC, dendritic cell; IL-6, interleukin-6; iNKT cell, invariant natural killer T cell; NAADP, nicotinic acid adenine dinucleotide phosphate; P2XR, P2X purinergic receptor; P2YR, P2Y purinergic receptor; RBC, red blood cell; $T_{\text {Reg }}$ cell, regulatory T cell; VEGF, vascular endothelial growth factor. * $P 2 X R s$ are composed of homotrimers except for $\mathrm{P} 2 \mathrm{X}_{6} \mathrm{R}$, which cannot form homotrimers. Heterotrimer $\mathrm{P} 2 \mathrm{X}$ Rs that consist of two different subunits have been reported: $\mathrm{P} 2 \mathrm{X}_{1 / 2} \mathrm{R}, \mathrm{P} 2 \mathrm{X}_{2 / 3} \mathrm{R}$, $P 2 X_{2 / 6} R$ and $P 2 X_{46} R$ (reviewed in REF. 209). ${ }^{\ddagger}$ Rodent P2Y Rs also bind ATP; P2Y ${ }_{11}$ Rs are absent in rodents. ${ }^{\S}=$ means the two compounds have equal potency. ${ }^{~}{ }^{2} A>B$ means compound $A$ has greater affinity than compound $B .{ }^{\# A}>>B$ means compound $A$ has a much greater affinity than $B$. 




Endothelial nitric oxide synthase

(eNOS). A Ca ${ }^{2+}$-calmodulindependent enzyme that

catalyses the production of the vasodilator nitric oxide $(\mathrm{NO})$ in endothelial cells. referred to as 'find me' signals ${ }^{5}$ that attract phagocytes, activate platelets and stimulate local endothelial nitric oxide synthase (eNOS)-dependent vasodilation. These events contribute to the acute inflammatory phase of purinergic signalling following tissue injury. Most immune cells express several P2XRs and P2YRs. TABLE 1 summarizes the distribution and effects of purinergic receptor activation on individual immune cells. Inotropic P2XRs are usually composed of homotrimers but sometime are composed of heterotrimers (TABLE 1) that bind ATP with an $\mathrm{EC}_{50}$ of $0.5-1 \mu \mathrm{M}$, with the exception of $\mathrm{P} 2 \mathrm{X}_{2} \mathrm{R}$ $(10 \mu \mathrm{M})$ and $\mathrm{P} 2 \mathrm{X}_{7} \mathrm{R}(100 \mu \mathrm{M})$. Following gating owing to ATP binding, these channels become permeable to $\mathrm{Na}^{+}$, $\mathrm{K}^{+}$and $\mathrm{Ca}^{2+}$. P2 $\mathrm{X}_{7} \mathrm{Rs}$ are unusual in that they have low affinity for ATP and hence are only activated in highly inflamed tissues. Moreover, $\mathrm{P}_{2} \mathrm{X}_{7}$ Rs can form large pores that allow passage of molecules as large as 900 daltons, including ATP itself. Among the metabotropic P2YRs, P2 $Y_{1} R, P 2 Y_{2} R, P 2 Y_{4} R$ and $P 2 Y_{6} R$ are coupled to $G_{4}$ proteins, and $\mathrm{P} 2 \mathrm{Y}_{12} \mathrm{R}, \mathrm{P} 2 \mathrm{Y}_{13} \mathrm{R}$ and $\mathrm{P} 2 \mathrm{Y}_{14} \mathrm{R}$ are coupled to $\mathrm{G}_{\mathrm{i}}$ proteins. These $\mathrm{G}_{\mathrm{q}}$ - and $\mathrm{G}_{\mathrm{i}}$-coupled receptors produce excitatory effects in immune cells by mobilizing calcium or reducing anti-inflammatory cAMP accumulation. $\mathrm{P}_{2} \mathrm{Y}_{11} \mathrm{Rs}$ are unusual in that they are dually coupled to $G_{q}$ and $G_{s}$ proteins, interact with $P 2 Y_{1} R s$ and are absent in rodents ${ }^{24}$. Notable among the effects of P2YR signalling are chemotaxis and activation of phagocytes in response to $\mathrm{P} 2 \mathrm{Y}_{2} \mathrm{R}^{25}$ or $\mathrm{P} 2 \mathrm{Y}_{14} \mathrm{R}^{26}$ activation. In summary, ATP and other nucleotides are rapidly released from injured tissues and function through several P2 purinergic receptors to attract and activate immune cells.

Overview of adenosine signalling in immune cells. Of the four adenosine receptor subtypes (A1R, A2AR, A2BR and $A 3 R$ ), the $G_{s}$ protein-coupled A2ARs and A2BRs are upregulated in response to activation of immune cells and respond to adenosine binding by generating cAMP, activating protein kinase A (PKA) and limiting inflammation during the subacute phase of inflammation following tissue injury. A2ARs are expressed on most immune cells, including $\mathrm{T}$ cells, invariant natural killer T (iNKT) cells, monocytes, macrophages, DCs, natural killer (NK) cells, platelets, mast cells, eosinophils and B cells (TABLE 1). Consistent with their generally antiinflammatory properties, global deletion of A2ARs in mice was found to enhance the effects of stimuli that promote inflammation or tissue injury ${ }^{27}$.

In the immune system, A2BRs are primarily expressed by macrophages and DCs and, at lower levels, by lymphocytes and platelets. A2BRs have lower affinity 
for adenosine than A2ARs and are generally only weakly activated except in inflamed tissues, in which adenosine levels are elevated. The importance of A2BR signalling is increased in inflamed tissues because these receptors are strongly upregulated in response to hypoxia and hypoxia-inducible factors (HIFs) ${ }^{28}$. In some cells, A2BRs have been found to both couple to $G_{s}$ protein and the calcium-mobilizing $\mathrm{G}_{\mathrm{q}}$ protein ${ }^{29}$. $\mathrm{G}_{\mathrm{q}}$ protein activation contributes to $\mathrm{A} 2 \mathrm{BR}$-mediated wound-healing responses, such as angiogenesis ${ }^{30}$ and fibrosis ${ }^{31}$, by promoting the production of vascular endothelial growth factor (VEGF) and interleukin-6 (IL-6); these mediators are produced more by $\mathrm{A} 2 \mathrm{BR}$ than $\mathrm{A} 2 \mathrm{AR}$ activation. Hence, A2BR signalling contributes to the chronic phase of wound healing following tissue injury. Although acute A2BR activation is anti-inflammatory, IL-6 production in response to $\mathrm{A} 2 \mathrm{BR}$ signalling can favour the polarization of naive $\mathrm{T}$ cells towards a pro-inflammatory $\mathrm{T}$ helper $17\left(\mathrm{~T}_{\mathrm{H}} 17\right)$ cell phenotype $\mathrm{e}^{32}$. This mechanism contributes to the persistent tissue remodelling and fibrosis that occurs in chronically inflamed tissues.

Purinergic regulation of thymic T cell development and of naive T cells. Immature thymocytes undergo selection in the thymus based on the signalling properties of their newly rearranged TCRs. Positive selection leads to the survival of thymocytes that express TCRs with a threshold affinity for MHC molecules, whereas negative selection causes apoptotic deletion of thymocytes that express TCRs with a high affinity for MHC or self-antigens. The rapid cell turnover and high levels of apoptotic cell death that occur in the thymic medulla result in high extracellular concentrations of ATP and adenosine ${ }^{33}$. High levels of ATP enhance thymocyte apoptosis owing to excitatory $\mathrm{P} 2 \mathrm{X}_{7} \mathrm{R}$ activation ${ }^{34}$. Expression of the IL-7 receptor subunit- $\alpha$ (IL-7R $\alpha$ ), which is needed for survival of thymic precursors, is reduced as a result of strong TCR activation, and this contributes to negative selection. TCR-dependent signalling and negative selection can be inhibited by activation of A2ARs that are upregulated during early thymocyte development and that inhibit the TCR signalling pathway. A2AR signalling is required for optimal progression of double-negative thymic precursors to single-positive thymocytes that have increased IL-7Ra expression $^{35}$ (FIG. 2a). Naive T cells that survive selection in the thymus undergo TCR-dependent homeostatic proliferation in the periphery. Similarly to thymocytes, IL-7Ra expression and survival of naive T cells is increased by A2AR activation ${ }^{35}$. The data suggest that $\mathrm{P} 2 \mathrm{X}_{7} \mathrm{R}$ signalling enhances, and A2AR signalling inhibits, TCR-mediated negative selection in the thymus and deletion of naive $\mathrm{T}$ cells in the periphery.

Purinergic regulation of effector $T$ cells. T cells are activated through their TCRs in response to cognate peptide-MHC complexes on antigen-presenting cells and co-stimulatory molecules such as CD80 and CD86. ATP enhances, whereas adenosine suppresses, TCRmediated responses (FIG. 2b). T cells themselves serve as a source of extracellular ATP as TCR stimulation induces the release of $\mathrm{ATP}^{36}$. Transcripts for all of the P2YRs, and for $\mathrm{P}_{2} \mathrm{X}_{1} \mathrm{R}$ and $\mathrm{P} 2 \mathrm{X}_{4} \mathrm{R}$ can be detected in lymphocytes, but the most highly expressed transcript is $\mathrm{P} 2 \mathrm{Y}_{12} \mathrm{R}$ (REF. 37). High expression of $\mathrm{P} 2 \mathrm{Y}_{12}$ Rs in lymphocytes may contribute to anti-inflammatory effects that have been observed in patients taking anti-platelet $\mathrm{P}_{2} \mathrm{Y}_{12} \mathrm{R}$ antagonists such as clopidogrel ${ }^{37}$. Removal of extracellular ATP or inhibition of $\mathrm{P} 2 \mathrm{Y}_{12}$ Rs inhibits $\mathrm{Ca}^{2+}$ entry, nuclear factor of activated T cells (NFAT) activation and IL-2 synthesis. The excitatory actions of ATP are opposed by adenosine, which supresses $\mathrm{T}$ cell activation. Activation of $\mathrm{T}_{\mathrm{H}} 1, \mathrm{~T}_{\mathrm{H}} 2$ or $\mathrm{T}_{\mathrm{H}} 17$ cells in the presence of adenosine inhibits their production of effector cytokines ${ }^{38}$. A2AR activation mainly counteracts TCR-mediated activation of immune cells by increasing intracellular levels of cAMP. This leads to PKA phosphorylation and activation of C-terminal SRC kinase (CSK), which inhibits LCK by phosphorylation of Y505 (REF. 39) and reduces downstream LCK-dependent activation of ZAP70, extracellular signal-regulated kinase 1 (ERK1; also known as MAPK3)-JUN N-terminal kinase (JNK; also known as MAPK8) and protein kinase C (PKC) ${ }^{40,41}$. PKA activation also activates cAMP-responsive element-binding protein 1 (CREB), which contributes to inhibition of the major pro-inflammatory transcription factor nuclear factor- $\kappa \mathrm{B}(\mathrm{NF}-\kappa \mathrm{B})^{42}$. In a similar manner to A2AR agonists, inhibitors of phosphodiesterase isozyme 4 (PDE4) - which is the principal enzyme that degrades cAMP in immune cells - also elevate intracellular cAMP levels and lead to PKA activation, attenuating TCR signalling ${ }^{42}$, $\mathrm{T}$ cell proliferation and inflammatory cytokine production. PDE4 inhibitors enhance adenosine signalling in most immune cells ${ }^{43}$ and have recently been showed to be effective for the treatment of psoriatic arthritis ${ }^{44}$.

In addition to its effects on CSK, PKA activation also reduces the expression of $\mathrm{K}_{\mathrm{Ca}} 3.1$ potassium channels (also known as SK4) in human $\mathrm{CD}^{+} \mathrm{T}$ cells to reduce IL-2 secretion ${ }^{45}$ and signal transducer and activator of transcription 5 (STAT5) activation ${ }^{46}$. Adenosineinduced suppression of IL-2 production limits T cell proliferation and responses to co-stimulatory signals because the reduction in IL-2 also reduces expression of the co-stimulatory molecules CD28 and CD2 (REF. 47). In addition, $\mathrm{T}$ cell activation triggers the induction of A2ARs and other negative feedback signals including SH2 domain-containing inositol-5-phosphatase 1 $(\mathrm{SHIP} 1)^{48}$ and suppressor of cytokine signalling (SOCS) family proteins ${ }^{49}$. Adenosine has been found to inhibit human $\mathrm{CD}^{+} \mathrm{T}$ cell responses by reducing $\mathrm{Ca}^{2+}$ influx, cytokine production (IL-2, interferon- $\gamma$ (IFN $\gamma$ ) and tumour necrosis factor (TNF)), cytotoxicity and proliferation $^{40,42,50}$. In summary, following tissue injury, ATP functions to augment effector $\mathrm{T}$ cell activation during acute inflammation by elevating $\mathrm{Ca}^{2+}$, whereas adenosine suppresses subacute activation of effector $\mathrm{T}$ cells by activating $\mathrm{G}_{\mathrm{s}}$-coupled A2ARs.

Purinergic regulation of $T_{\text {Reg }}$ cells. Mouse regulatory $\mathrm{T}\left(\mathrm{T}_{\text {Reg }}\right)$ cells express high levels of CD39 and CD73, which are ectoenzymes that decrease the concentration of pro-inflammatory ATP while simultaneously 


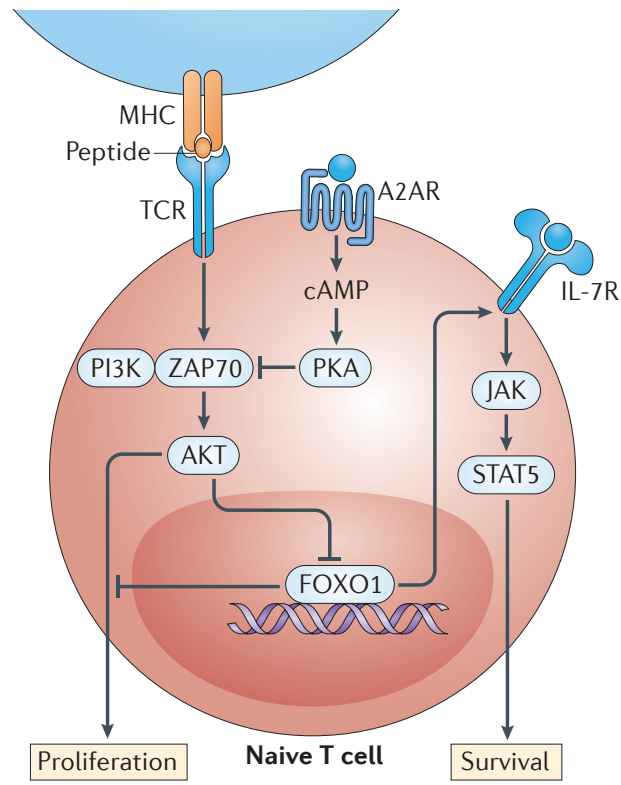

b

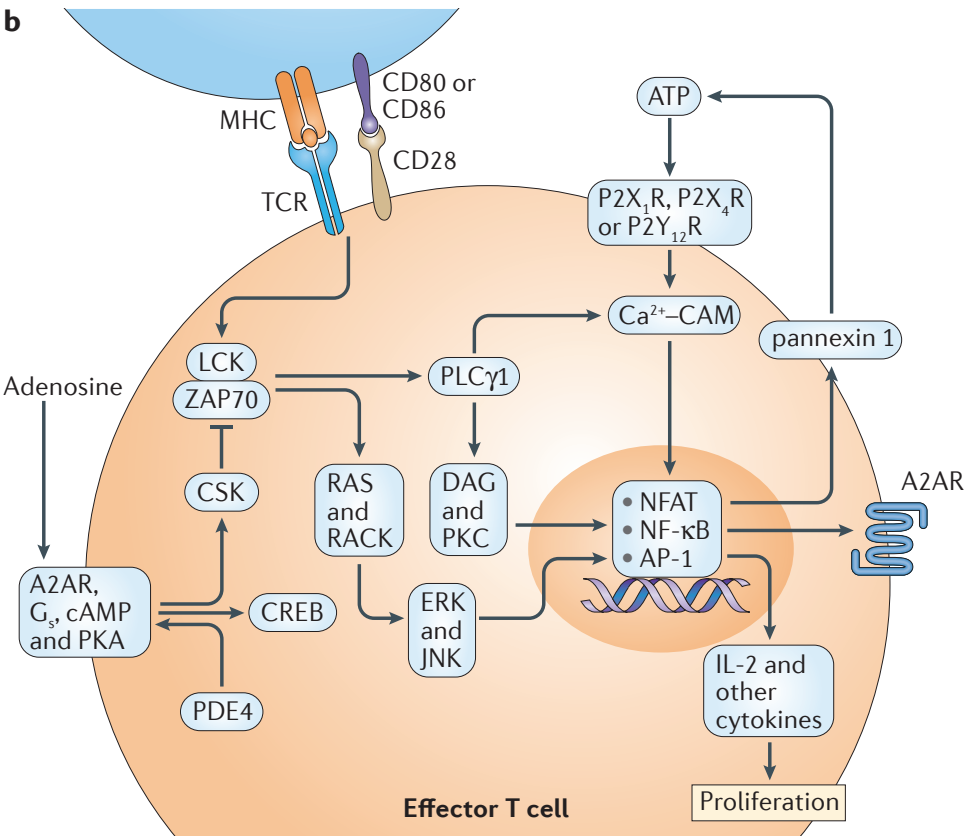

c

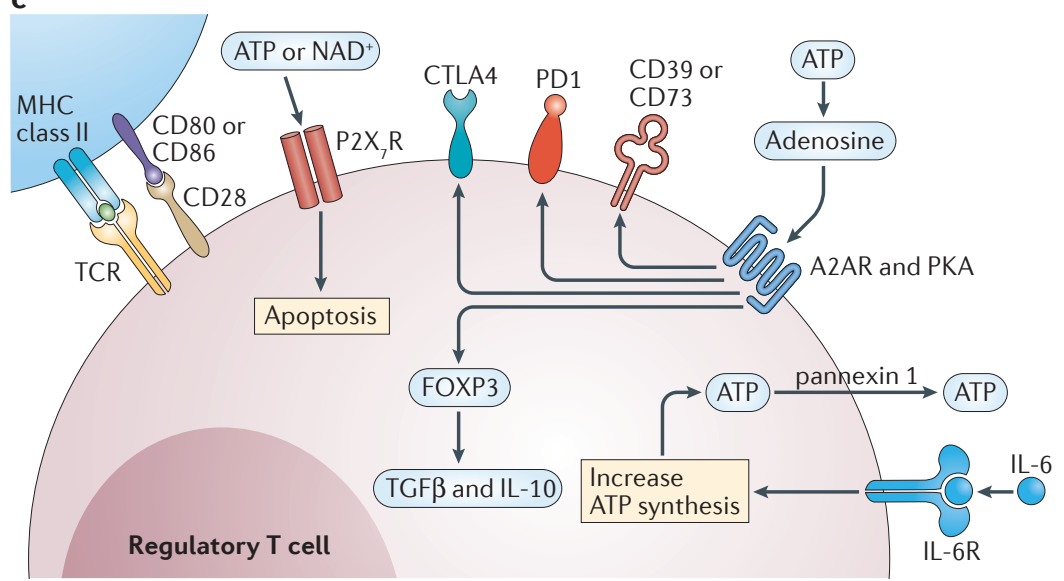

increasing the concentration of anti-inflammatory adenosine in the local microenvironment ${ }^{51}$. During acute inflammation, the activation of $\mathrm{P}_{2} \mathrm{X}_{7} \mathrm{Rs}$ on $\mathrm{T}_{\mathrm{Reg}}$ cells by ATP inhibits their suppressive activity and viability ${ }^{52}$ (FIG. 2c). Acute tissue injury causes the release not only of ATP but also of high amounts of IL-6. Exposure of $\mathrm{T}_{\text {Reg }}$ cells to IL- 6 increases their rate of ATP synthesis and release. The resultant increase in $\mathrm{P}_{2} \mathrm{X}_{7} \mathrm{R}$-mediated signalling favours $\mathrm{T}$ cell polarization into IL-17-secreting $\mathrm{T}_{\mathrm{H}} 17$ cells in vivo ${ }^{52,53}$. Moreover, pharmacological antagonism of P2XRs favours the polarization of naive $\mathrm{CD} 4^{+}$ $\mathrm{T}$ cells into $\mathrm{T}_{\text {Reg }}$ cells $\mathrm{s}^{52}$.

In mice, the $\mathrm{P} 2 \mathrm{X}_{7} \mathrm{R}$ channel can be activated not only by high concentrations of extracellular ATP but also by extracellular $\mathrm{NAD}^{+}$, which is a substrate for ectoenzymes that catalyse ADP-ribosylation and activation of $\mathrm{P} 2 \mathrm{X}_{7} \mathrm{Rs}^{54}$. As $\mathrm{T}_{\mathrm{Reg}}$ cells express high levels of $\mathrm{P} 2 \mathrm{X}_{7} \mathrm{Rs}$, they are very sensitive to $\mathrm{NAD}^{+}$-induced cell death ${ }^{54}$. By contrast, activation of A2ARs increases the formation of $\mathrm{T}_{\text {Reg }}$ cells $s^{55}$. In addition, adenosine-mediated A2AR signalling is needed to maintain CD73 and programmed cell death protein 1 (PD1) expression on $\mathrm{T}_{\mathrm{Reg}}$ cells; CD73-deletion or PD1 blockade before adoptive $\mathrm{T}_{\mathrm{Reg}}$ cell transfer phenocopies the reduced immunosupressive

Figure 2 | Purinergic signalling in T cells. a | In naive T cells, low-strength T cell receptor (TCR) activation stimulates proliferation but strong activation causes apoptosis owing to a reduction in the expression of interleukin-7 receptors (IL-7Rs) that are necessary for T cell survival. By dampening the TCR signalling cascade, A2A adenosine receptor (A2AR) engagement can enhance naive T cell survival by maintaining IL-7R expression. $\mathbf{b}$ | In effector T cells, extracellular ATP stimulates $\mathrm{Ca}^{2+}$ entry through $\mathrm{P} 2 \mathrm{X}$ purinergic receptor (P2XR) channels and $\mathrm{Ca}^{2+}$ mobilization (P2YR) to facilitate $\mathrm{Ca}^{2+}$ calmodulin (CAM)-dependent activation and nuclear translocation of nuclear factor of activated T cells (NFAT), which stimulates the production of IL-2, pannexin 1 channels and other NFAT targets. Autocrine ATP release helps to sustain P2 purinergic receptor signalling and NFAT activation. Extracellular adenosine and inhibitors of phosphodiesterase isozyme 4 (PDE4) elevate cAMP and activate protein kinase $A(P K A)$, which activates C-terminal SRC kinase (CSK), a negative regulator of $L C K$. This attenuates the activation of transcription factors that are downstream of TCR activation, including NFAT, nuclear factor- $\kappa \mathrm{B}$ (NF- $\kappa \mathrm{B}$ ) and AP-1.TCR activation increases $\mathrm{A} 2 \mathrm{ARs}$ through $\mathrm{NF}$ - $\mathrm{KB}$-dependent induction. $\mathbf{c} \mid$ In regulatory T cells, high expression of cell surface CD39 and CD73 rapidly converts locally produced pro-inflammatory ATP to anti-inflammatory adenosine. IL-6 signalling enhances the autocrine production and release of ATP. High levels of ATP or $\mathrm{NAD}^{+}$can stimulate apoptosis owing to pore formation by $\mathrm{P} 2 \mathrm{X}_{7} \mathrm{Rs}$. Adenosine activates A2ARs and increases the expression of CD39, CD73, programmed cell death protein 1 (PD1) and forkhead box P3 (FOXP3). CREB, cAMP-responsive element-binding protein; CTLA4, cytotoxic T lymphocyte antigen 4; DAG, dystrophinassociated glycoprotein; ERK, extracellular signal-regulated kinase; FOXO1, forkhead box O1; JAK, Janus kinase; JNK, JUN $\mathrm{N}$-terminal kinase; PI3K, phosphoinositide 3-kinase; PKC, protein kinase C; PLC $\gamma 1$, phospholipase $C \gamma 1$; RACK, receptor for activated C-kinase; STAT5, signal transducer and activator of transcription 5; TGF $\beta$, transforming growth factor- $\beta$. 


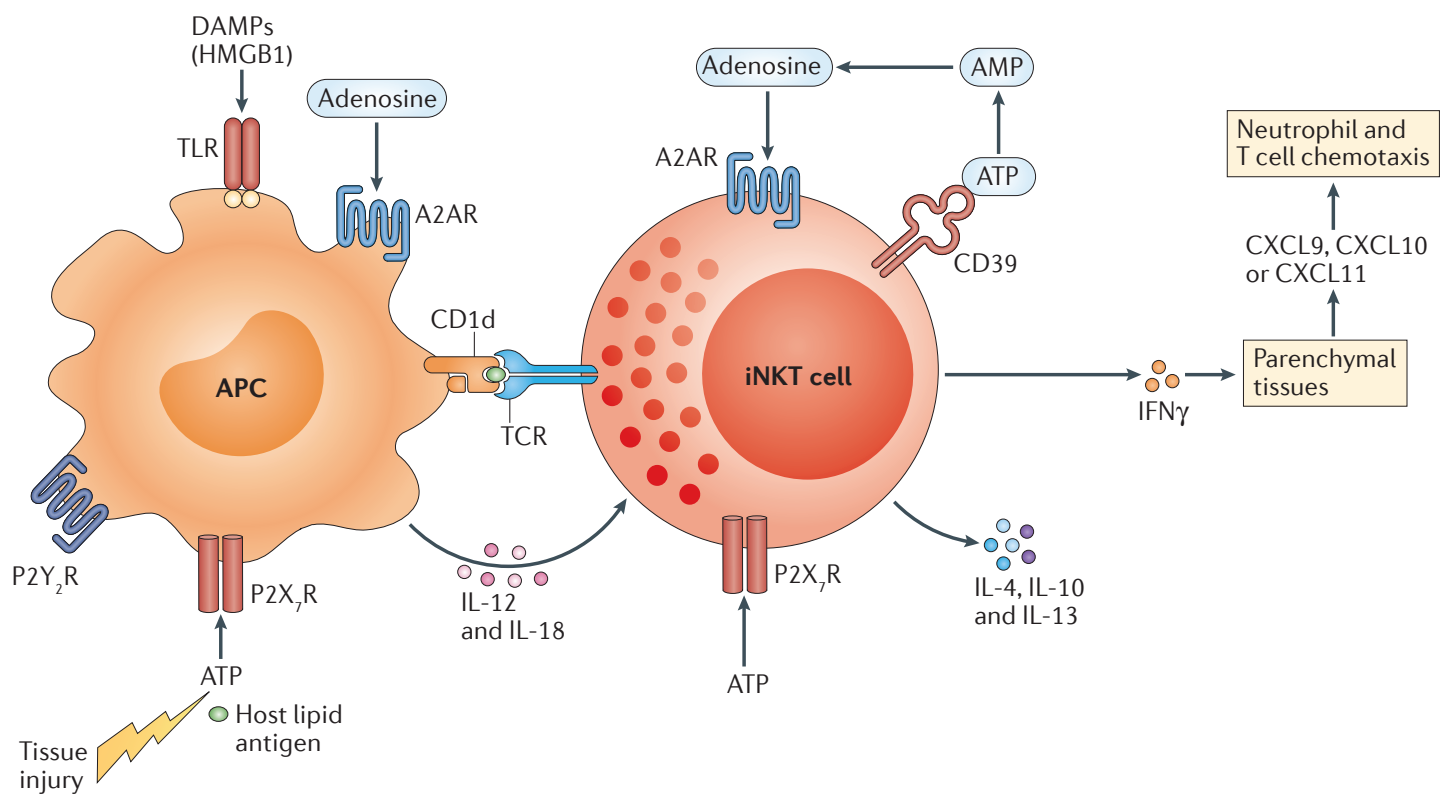

Figure 3 | Purinergic signalling in iNKT cells. Sterile tissue injury resulting from tissue ischaemia or tissue transplantation results in the release of damage-associated molecular patterns (DAMPs), such as ATP and high mobility group box 1 (HMGB1), that enhance the production in antigen-presenting cells (APCs) of CD1d-restricted lipid antigens and co-stimulatory cytokines (interleukin-12 (IL-12) and IL-18). Lipid antigens, IL-12, IL-18 and ATP stimulate invariant natural killer T (iNKT) cells to produce a mixture of pro-inflammatory (interferon- $\gamma$ (IFN $\gamma$ )) and anti-inflammatory (IL-4 and IL-13) cytokines. IFN $\gamma$ stimulates the production of IFN $\gamma$-inducible cytokines (CXC-chemokine ligand 9 (CXCL9), CXCL10 and CXCL11) that are chemotactic to neutrophils. iNKT cell activation causes the induction of A2A adenosine receptors (A2ARs) and CD39 to enhance adenosine signalling through A2ARs. A2AR activation inhibits IFN $\gamma$ production and stimulates IL-4 and IL-13 production, accelerates the conversion of ATP to adenosine and inhibits tissue inflammation and injury. ; $2 X_{7}$ R, P2X purinergic receptor; TCR, T cell receptor; TLR, Toll-like receptor.

activity that is caused by A2AR deletion ${ }^{56} . \mathrm{T}_{\mathrm{Reg}}$ cells also secrete exosomes containing CD39 and CD73, and these exosomes have been found to suppress effector $\mathrm{T}$ cell proliferation and IL-2 secretion ${ }^{57}$.

In humans, but not mice, CD73 is expressed on most B cells. CD39 expression accounts for strong immunosupressive activity by human mesenchymal stromal cells ${ }^{58}$. CD39 expression also identifies subsets of human $\mathrm{CD} 4^{+} \mathrm{T}$ cells that are either potent $\mathrm{T}_{\mathrm{Reg}}$ cells or that can convert to $\mathrm{T}_{\mathrm{Reg}}$ cells under pathological conditions ${ }^{59}$. Adenosine produced as a result of the enzymatic activity of CD39 and CD73 has been implicated in the progressive immunosuppression that occurs in patients with AIDS ${ }^{60}$. Numbers of CD $39^{+} \mathrm{T}_{\mathrm{Reg}}$ cells are increased following HIV infection ${ }^{61-63}$, and genetic studies have shown that a CD39 gene polymorphism that is associated with reduced levels of CD39 expression slows progression to AIDS in patients infected with $\mathrm{HIV}^{60}$.

In summary, ATP-mediated signalling reduces the viability of $\mathrm{T}_{\mathrm{Reg}}$ cells and favours the formation of $\mathrm{T}_{\mathrm{H}} 17$ cells. Adenosine signalling increases numbers of $\mathrm{T}_{\text {Reg }}$ cells, maintains their expression of CD73 and PD1, and supresses the activation of DCs and effector T cells.

CD1d-restricted

Natural killer T (NKT) cells that are activated by lipid antigens presented in the binding cleft of the MHC class Ib molecule CD1d. cells are rapidly activated in infected or injured tissues in response to stimulation of their invariant TCR by CD 1d-restricted lipid antigens or in response to IL-12 and IL-18 (REFS 64,65). iNKT cells also express excitatory P2XRs and P2YRs ${ }^{66}$ (FIG. 3). Once activated, iNKT cells propagate an inflammatory cascade that can exacerbate tissue injury ${ }^{67-69}$. CD1d-restricted lipid antigens are produced by various pathogens and by damaged host tissues $^{70}$. Upon stimulation by lipid antigens, most iNKT cells rapidly produce IFN $\gamma$, which functions to stimulate IFN $\gamma$-inducible chemokines (CXC-chemokine ligand 9 (CXCL9), CXCL10 and CXCL11) and IL-17 that are responsible for chemotaxis of other inflammatory cells, including neutrophils ${ }^{71,72}$. In the mouse liver, concanavalin A induces injury that is mediated by iNKT cell activation. Deletion of CD39 was unexpectedly found to protect the liver from concanavalin A-induced hepatitis $^{66}$. This was attributed to ATP-dependent pore formation and iNKT cell apoptosis and may occur only as a result of severe inflammation.

As is the case in conventional T cells, A2AR is induced in iNKT cells in response to NF- $\kappa \mathrm{B}$ activation ${ }^{73}$. Stimulation of A2ARs on iNKT cells limits iNKT cell activation and decreases their production of IFN $\gamma$ while simultaneously increasing their production of transforming growth factor- $\beta$ (TGF $\beta$ ) and IL-10 (REF. 73). Hence, inflammation caused by iNKT cell activation following the acute phase of tissue injury is substantially reduced by activation of A2ARs on iNKT cells ${ }^{67}$. 
a-galactosylceramide (aGalCer). A glycolipid antigen of invariant natural killer T (iNKT) cells.
Preconditioning mice with the CD1d-restricted lipid antigen $\alpha$-galactosylceramide ( $\alpha \mathrm{GalCer}$ ) was found to protect the liver from ischaemia-reperfusion injury by increasing the expression of A2ARs on iNKT cells
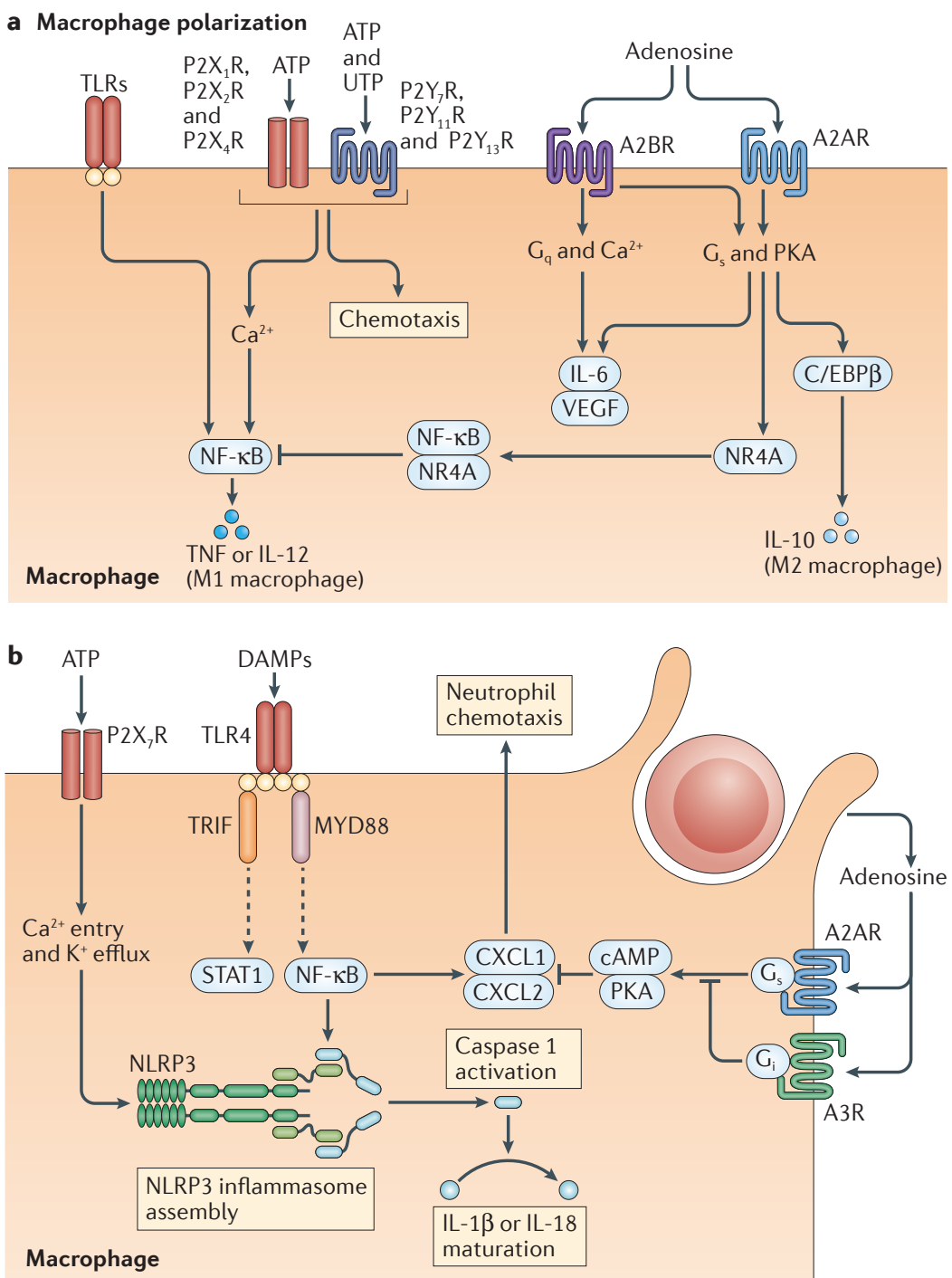

Figure 4 | Purinergic signalling in monocytes and macrophages. a | In monocytes, ATP and UTP released from inflamed tissues are chemotactic to monocytes, activate nuclear factor- $\mathrm{kB}$ (NF- $\mathrm{kB}$ ) and favour monocyte polarization into pro-inflammatory (M1) macrophages. Adenosine signalling through A2A adenosine receptors (A2ARs) and A2BRs activates nuclear receptor subfamily 4 group A (NR4A) transcription factors that inhibit NF- $\kappa B$ activation and favour monocyte polarization into anti-inflammatory (M2) macrophages. A2AR and A2BR signalling increase levels of cAMP and $\mathrm{Ca}^{2+}$, which, along with hypoxia, increases angiogenesis by induction of vascular endothelial growth factor (VEGF). Protein kinase A (PKA) and cAMP-responsive element-binding protein (CREB)-dependent activation of CCAAT/enhancer-binding protein- $\beta$ (C/EBP $\beta$ ) increases anti-inflammatory interleukin-10 (IL-10) production. $\mathbf{b}$ | In macrophages, activation of P2 $\mathrm{X}_{7}$ purinergic receptors (P2X Rs) by ATP helps to activate the NLRP3 (NOD-, LRR- and pyrin domain-containing 3 ) inflammasome and caspase 1 to trigger the proteolytic maturation of IL-1 $\beta$ and other cytokines. Engulfment of apoptotic cells by macrophages stimulates the production of cytokines (CXCL1 and CXCL2) that are chemotactic to neutrophils. Chemokine production is regulated by inhibitory A2ARs and stimulatory A3Rs. DAMP, damage-associated molecular pattern; STAT1, signal transducer and activator of transcription 1; TLR, Toll-like receptor; TNF, tumour necrosis factor; TRIF, TIR domain-containing adaptor protein inducing IFN $\beta$. and by enhancing their production of IL-13. Blocking A2ARs with selective antagonists reversed these protective effects $^{74}$.

Stimulation of A2ARs on iNKT cells has been found to have a protective effect in sickle cell disease, in which iNKT cells have a major role in causing tissue inflammation and injury during vaso-occlusive events ${ }^{75}$. The adoptive transfer of iNKT cells worsened pulmonary function in NY1DD mice deficient in recombination-activating protein 1 (RAG1): a model of sickle cell disease in mice lacking T cells. Treatment of NY1DD Rag1/- mice with A2AR agonists prevented adoptively transferred iNKT cells from causing pulmonary inflammation in this model $^{75}$. Similar findings have been reported in human studies; iNKT cells collected from the blood of patients with sickle cell disease during painful vaso-occlusive crises showed elevated levels of NF- $\kappa \mathrm{B}$ activation and cytokine production that could be decreased by infusion of an A2AR agonist, regadenoson ${ }^{76}$.

In summary, an important mechanism by which adenosine inhibits tissue damage during ischaemiareperfusion injury is by signalling through A2ARs on iNKT cells. As a consequence, A2AR agonists and antibodies that deplete iNKT cells have potential utility for treating ischaemia-reperfusion injury that occurs in different clinical settings, including in myocardial infarction, tissue transplantation and sickle cell disease.

Monocytes, macrophages, DCs and neutrophils. During the acute phase of inflammation following tissue injury, ATP and UTP released from apoptotic cells signal through P2 purinergic receptors to recruit monocytes, DCs and neutrophils ${ }^{23,77}$. All monocyte and macrophage cell lines have been found to express P2XRs and P2YRs. In monocytes, the most abundant $\mathrm{P} 2 \mathrm{XR}$ transcripts are $\mathrm{P} 2 \mathrm{X}_{4} \mathrm{R}$, followed by transcripts for $\mathrm{P} 2 \mathrm{X}_{7} \mathrm{R}$ and $\mathrm{P} 2 \mathrm{X}_{1} \mathrm{R}^{37}$. These transcripts are expressed at much higher levels in monocytes than in lymphocytes, suggesting that they may have an important role in monocyte chemotaxis and activation. In highly inflamed tissues, ATP that is released from stressed or damaged cells binds to low affinity $\mathrm{P}_{2} \mathrm{X}_{7}$ Rs on macrophages, activates the inflammasome and stimulates secretion of IL- $1 \beta$, which is required for optimal polarization of IFN $\gamma$-producing $\mathrm{CD}^{+} \mathrm{T}$ cells ${ }^{78}$. $\mathrm{A} 2 \mathrm{BR}$ expression on myeloid cells increases in response to IFN $\gamma$ and limits expression of IL- $1 \beta$, as well as MHC class II and TNF. A2BR signalling also induces production of pro-fibrotic IL-6 and IL-8, especially under hypoxic conditions, through mitogen-activated protein kinase (MAPK) and AP-1 (REFS 79,80).

With regards to P2YRs in monocytes, transcripts for $\mathrm{P} 2 \mathrm{Y}_{13} \mathrm{R}$ and $\mathrm{P} 2 \mathrm{Y}_{2} \mathrm{R}$ are most abundant, followed by transcript for $\mathrm{P}_{2} \mathrm{Y}_{11} \mathrm{R}$. Monocytes that enter injured tissues can polarize into pro-inflammatory (M1) macrophages or tolerogenic or pro-angiogenic (M2) macrophages (FIG. 4a). The tolerogenic M2 phenotype is produced in response to adenosine and is characterized by low expression of pro-inflammatory mediators, such as TNF and IL-12, and high expression of tolerogenic markers, such as IL-10, arginase 1 and $\mathrm{VEGF}^{81-84}$. Adenosine inhibits macrophage production 


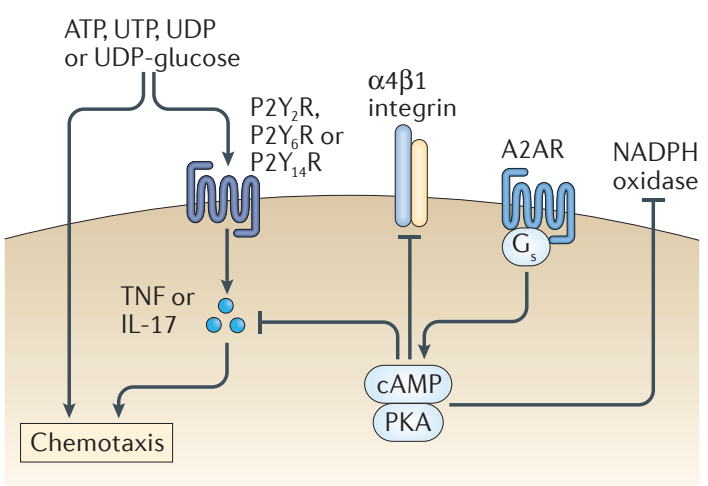

Figure 5 | Purinergic signalling in neutrophils. In neutrophils, ATP, UPT and other nucleotides released from inflamed tissues are directly chemotactic and stimulate the production of chemotactic cytokines. Adenosine signals through A2A adenosine receptors (A2ARs) to inhibit production of cytokines, inhibit superoxide production by NADPH oxidase and decrease the expression of adhesion molecules such as $\alpha 4 \beta 1$ integrin. IL-17, interleukin-17; PKA, protein kinase A; TNF, tumour necrosis factor.

of pro-inflammatory cytokines and increases antiinflammatory IL-10 in response to lipopolysaccharide or Tat (an HIV protein) ${ }^{85}$. A2AR activation in conjunction with antibiotics produces a significant survival benefit in mice infected with live Escherichia coli or Staphylococcus aureus because A2AR signalling suppresses the cytokine storm that occurs in response to rapid bacterial killing. In mice, both A2ARs and A2BRs contribute to adenosine regulation of peritoneal macrophages, whereas A2BR-mediated signalling predominates in RAW 264.7 cells and mouse bone marrow-derived macrophages. Inflammation increases expression of A2ARs to limit inflammatory responses. The promoter region of A2AR contains binding sites for NF- $\kappa \mathrm{B}, \mathrm{STAT} 1$ and peroxisome proliferator-activated receptor- $\gamma(\operatorname{PPAR} \gamma)$, and activation of these transcription factors induces A2AR expression ${ }^{86-88}$. Human A2AR expression is also modified by microRNA-214 (miR-214), miR-15 and miR-16 (REF. 89).

During the subacute phase following tissue injury (FIC. 1), apoptotic cells are engulfed by macrophages, and adenosine is produced in sufficient quantities to activate both A2ARs and A3Rs. A2AR signalling activates $G_{s}$ proteins and suppresses apoptotic cell-induced formation of the neutrophil migration factors CXCL1 (also known as KC) and CXCL2 (also known as MIP2) ${ }^{90}$ (FIG. 4b). This is countered by activation of $\mathrm{G}_{i}$ proteincoupled A3Rs. As a result, the balance in the activation of A2ARs and A3Rs determines the amount of neutrophil chemoattractants formed. As the expression of A2ARs increases and A3Rs decreases over time during phagocytosis of apoptotic cells, adenosine gradually becomes more suppressive of the pro-inflammatory signals produced as a result of macrophage engulfment of apoptotic cells ${ }^{90}$.

In both mice and humans, adenosine inhibits DC maturation and their production of effector cytokines needed for $\mathrm{T}_{\mathrm{H}} 1$ cell differentiation (IL-12 and TNF), and increases their production of pro-angiogenic VEGF, IL-10 and cytokines that contribute to $\mathrm{T}_{\mathrm{H}} 17$ cell

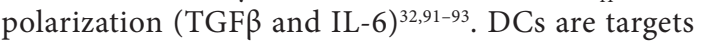
for immune suppression by $\mathrm{T}_{\mathrm{Reg}}$ cells that attract $\mathrm{DCs}$ by activating exchange protein directly activated by cAMP 1 (EPAC1)-repressor/activator protein 1 homologue (RAP1)-dependent pathways ${ }^{94}$. Clusters of DCs and $\mathrm{T}_{\mathrm{Reg}}$ cells degrade ATP to adenosine through CD39 and $\mathrm{CD} 73$, and $\mathrm{A} 2 \mathrm{AR}$ activation stimulates secretion of inhibitory cytokines by DCs. Immature human DCs express A1Rs and A3Rs that promote their migration towards adenosine in inflamed tissues. DC maturation is associated with decreased expression of A1Rs and A3Rs, and increased expression of A2ARs ${ }^{95-97}$. Adenosine signalling promotes DC polarization into a tolerogenic phenotype that is characterized by the expression of arginase 1 , arginase 2 and indoleamine 2,3-dioxygenase (IDO) ${ }^{98}$. DCs also express A2BRs that are induced by hypoxia and/or HIF-1 $\alpha^{99-102}$. Because adenosine generally has a suppressive role in DC maturation and activation, adenosine deaminase (ADA) deficiency, which causes high systemic adenosine levels, increases tolerogenic and angiogenic DCs ${ }^{98}$. Interestingly, increased ADA expression can increase immunogenicity of human DCs by degrading adenosine and by promoting the formation of stable immunological synapses ${ }^{103-105}$. ADA on the surface of human DCs interacts with the ADA-binding protein CD26 (also known as DPP4) on the surface of T cells. When this occurs, up to threefold less antigen is needed to achieve $\mathrm{T}$ cell priming ${ }^{105}$. Adenosine-mediated differentiation of DCs into angiogenic or tolerogenic phenotypes has been shown to be functionally immunosuppressive. As an example, adenosine treatment of DCs loaded with aGalCer before adoptive cell transfer prevents ischaemia-reperfusion-induced kidney injury. Such tolerized DCs were found to increase serum levels of IL-10 and to decrease IFN $\gamma^{91}$. It has been suggested that high concentrations of adenosine that are detected in aqueous pollen extracts may be responsible for $\mathrm{T}_{\mathrm{H}} 2$ cell-promoting effects of pollen on human DCs ${ }^{106}$. Treatment of DCs with adenosine also promotes solid tumour growth and neovascularization ${ }^{98,107}$. Bacteria also exploit immunosuppressive adenosine signalling to reduce DC and T cell activation ${ }^{100}$.

Neutrophils function to kill pathogens but can also produce damage to the host, especially in the setting of sterile inflammation that occurs following tissue transplantation or ischaemia-reperfusion injury. As summarized in TABLE 1 and FIG. 5, ATP, UTP, UDP and UDP-glucose released from injured tissues are chemotactic by engaging $\mathrm{P} 2 \mathrm{Y}_{2} \mathrm{R}, \mathrm{P} 2 \mathrm{Y}_{6} \mathrm{R}$ and $\mathrm{P} 2 \mathrm{Y}_{14} \mathrm{R}$ on neutrophils. Chemotaxis is also stimulated by A3R activation and is reduced in the presence of selective A3AR agonists that may disrupt the adenosine chemotactic gradient or by antagonists that block A3R signalling. Pharmaceutical approaches that target these receptors might be useful to control acute lung injury due to excessive neutrophil influx in sepsis ${ }^{108}$. In addition to direct effects of adenosine on neutrophils, A2AR activation produces indirect inhibitory effects on neutrophil chemotaxis by 
reducing the production of chemotactic factors such as TNF, IL-17 (REFS 109,110), CXCL1, CXCL2 and/or CXCL3 (REF. 111). Activation of A2ARs on neutrophils also causes cAMP-dependent inhibition of oxidative activity $^{112}$ and inhibits expression of $\alpha 4 \beta 1$ integrin (also known as VLA4) that mediates their adhesion to endothelial cells ${ }^{113}$.

In summary, purines released from apoptotic cells have been found to have a central role in stimulating phagocyte chemotaxis and activation by engaging $\mathrm{P} 2 \mathrm{XRs}$ and P2YRs. Adenosine inhibits phagocyte chemotaxis and activation through both direct and indirect effects that are mediated by A2ARs and A2BRs. Targeting P2X, P2Y and adenosine receptors may be useful for reducing excessive inflammation that can occur as a result of ischaemia-reperfusion injury, cytokine storm in sepsis and autoimmunity. A2BR blockade to reduce IL-6 production may be useful for the treatment of renal ${ }^{114}$, cardiac $^{115}$, penile ${ }^{116}$ and pulmonary ${ }^{31}$ fibrotic diseases.

\section{Tissue protection by adenosine}

In the sections above, we have summarized some of the key ways in which purinergic signalling affects immune cell function. Below, we discuss how purinergic signalling shapes the immune responses that occur in tissues in the context of ischaemia, autoimmunity and cancer.

Adenosine signalling in the ischaemic heart. Ischaemic preconditioning (IPC) is a protective phenomenon in which a brief episode of ischaemia renders the myocardium (and other tissues) resistant to subsequent ischaemic insults. IPC consists of two phases, an acute phase (early IPC) that develops immediately but wanes within $1-2 \mathrm{~h}$, and a delayed phase (late IPC) that appears after $12-24 \mathrm{~h}$ and lasts for several days. Adenosine has a key role in IPC, and all four adenosine receptors have been implicated. Activation of A1R is a mediator of both early and late IPC ${ }^{117}$. Early IPC mediated by A1R activation is blocked by glybenclamide, an inhibitor of ATP-sensitive $\mathrm{K}^{+}$channels ${ }^{117}$. The role of A2BR in IPC is controversial; it seems to be important for mediating late states of IPC that depend on the induction of stress-responsive genes but, at least in some animal models, is not involved in early IPC ${ }^{118}$. A2AR activation on bone marrow-derived cells, particularly iNKT cells, is responsible for some of the infarct-sparing and antiinflammatory effects of A2AR agonists administered at the time of reperfusion after coronary occlusion ${ }^{119}$. The infarct-sparing effect of A2AR activation is associated with inhibition of $\mathrm{CD} 4^{+} \mathrm{T}$ cells (probably iNKT cells) (FIG. 3) in the reperfused heart ${ }^{120}$. A cardioprotective effect of activating A3R in rodents may be due to mast cell stimulation with release of ATP, metabolism of ATP to adenosine and secondary activation of A2ARs on bone marrow-derived cells ${ }^{121}$. A2AR activation holds promise as a therapy to reduce infarct size after myocardial infarction, as A2AR agonists can be administered during stenting following angioplasty of infarcted coronary arteries and limit injury after myocardial infarction. The AMISTAD II trial was conducted to determine whether intravenous adenosine administered to patients reduced infarct sizes following acute myocardial infarction. Adenosine failed to significantly reduce total infarct size in the AMISTAD II trial, but in a subset of patients, adenosine infusion was found to significantly reduce infarct size normalized to area at risk, which is a more precise measure of myocardial injury ${ }^{122}$. These data suggest that adenosine or A2AR agonists administered just before stenting have the potential to reduce myocardial infarct size.

Remodelling of the heart occurs after myocardial infarction, leading to fibrosis, dysfunction and ventricular tachycardia. Adenosine, through A2BR, has been implicated in promoting these adverse outcomes. Treatment of rats with an A2BR blocker beginning 1 week after myocardial infarction resulted in improved cardiac function and decreased susceptibility to ventricular tachycardia ${ }^{115}$. The use of A2BR antagonists is a promising strategy for preventing adverse tissue remodelling after tissue ischaemia.

Adenosine signalling in the ischaemic kidney. Adenosine holds promise for protecting the kidneys during renal ischaemia or renal transplantation. CD73-deficient mice progressively develop renal failure that is associated with autoimmune inflammatory reactions that are characterized by increased production of pro-inflammatory cytokines, IgG deposition and immune cell infiltration in the kidneys. These findings suggest that adenosine can protect the kidney by preventing the development of autoimmune and inflammatory reactions ${ }^{123}$. All four adenosine receptors have been implicated in renal protection. Activation of A1R stimulated phosphoinositide 3-kinase (PI3K) and PKC signalling that significantly reduced necrosis and apoptosis in renal tissue after ischaemia ${ }^{124-126}$. In both acute and chronic forms of kidney diseases (for example, diabetic nephropathy), A2AR signalling in macrophages, dendritic cells and iNKT cells attenuates renal injury ${ }^{56,91,127-130}$. Mechanistically, A2AR activation enhances IL-10 production, inhibits macrophage infiltration, suppresses the production of pro-inflammatory cytokines by T cells and myeloid cells and increases $\mathrm{T}_{\mathrm{Reg}}$ cell expression of PD1 to provide tissue protection ${ }^{56,91,130}$. Acute A2BR signalling can also contribute to tissue protection following acute kidney injury owing to ischaemia by suppressing TNF release ${ }^{131}$. A2BR activation on resident renal cells, but not on bone marrow-derived cells, also reduces renal inflammation ${ }^{132,133}$.

Adenosine signalling in the inflamed lung. Adenosine influences alveolar function and tissue inflammation in lung diseases. During subacute lung injury, adenosine targets A2ARs on immune cells and A2BR and A3R on both haematopoietic and non-haematopoietic cells to suppress lung inflammation and reduce pulmonary oedema and tissue damage ${ }^{134-136}$. During ischaemia, A2AR signalling in lung-resident cells, neutrophils and $\mathrm{CD}^{+} \mathrm{T}$ cells strongly reduces oedema and microvascular permeability and suppresses the production of pro-inflammatory cytokines and chemokines, such as TNF, IL-17 and CXCL1, thereby improving pulmonary 
function ${ }^{137,138}$. A2AR stimulation may be of use for preventing the development of acute chest syndrome in sickle cell disease $\mathrm{e}^{75}$ and for reducing inflammation and organ rejection following lung transplantation.

Chronic pulmonary inflammatory states, such as asthma and chronic obstructive pulmonary disease produce activation of A2BR signalling that enhances eosinophilic disease severity by increasing $\mathrm{T}_{\mathrm{H}} 2$-type cytokine production and eosinophil recruitment and degranulation ${ }^{139,140}$. Stimulation of A2BRs on human mast cells stimulates secretion of IL-4 that enhances IgE synthesis by B cells to enhance allergic inflammation ${ }^{141}$. A2BR activation also stimulates the production of IL- 6 by myeloid cells and facilitates IL-6-dependent pulmonary fibrosis ${ }^{142,143}$. In summary, A2AR agonists have potential for the treatment of acute lung inflammation that occurs in response to lung transplantation or acute chest syndrome. A2BR antagonists have potential for the treatment of asthma and pulmonary fibrosis.

\section{Transplant rejection and autoimmunity}

ATP signalling generally enhances rejection of transplanted tissues and autoimmune responses. ATP release is increased by the anaphylatoxin C3a that is generated as a result of transplant rejection ${ }^{11}$. Blockade of $\mathrm{P}_{2} \mathrm{X}_{7} \mathrm{Rs}$ was found to diminish $\mathrm{T}_{\mathrm{H}} 1$ - and $\mathrm{T}_{\mathrm{H}} 17$-type cytokine production in response to $\mathrm{T}$ cell activation and to inhibit the rejection of allografts ${ }^{144}$. Conversely, $C d 39^{-/-}$ $\mathrm{T}_{\text {Reg }}$ cells that are impaired in their ability to metabolize ATP failed to promote tolerance to allogeneic skin grafts despite expressing high levels of CD25 (also known as IL-2Ra) and cytotoxic T lymphocyte antigen 4 $(\text { CTLA4 })^{51}$. Oxidized ATP, which is a non-selective inhibitor of the ATP receptors, reduced proliferation and effector function of T cells ${ }^{145}$. Oxidized ATP also reduced $\mathrm{T}$ cell-mediated autoimmune type 1 diabetes and experimental autoimmune encephalomyelitis (EAE) in mice ${ }^{145}$. Hence, $\mathrm{P} 2$ purinergic receptor antagonists may be useful for reducing transplant rejection and for the treatment of autoimmune diseases.

A2AR signalling has been found to inhibit autoimmune responses in many disease models. In allogeneic mixed lymphocyte reactions, A2AR stimulation expanded $\mathrm{T}_{\mathrm{Reg}}$ cell populations ${ }^{146}$ and enhanced their expression of CD39, CD73 and CTLA4 (REF. 146). A2AR activation on lymphoid, non-lymphoid and non-haematopoietic cells all significantly contributed to reducing autoimmune and inflammatory reactions in colitis and inflammatory bowel disease models; therefore, reducing tissue damage, weight loss and gut permeability ${ }^{147-149}$. The transfer of wild-type $\mathrm{T}_{\text {Reg }}$ cells prevents colitis induced by pathogenic T cells, whereas $\mathrm{T}_{\text {Reg }}$ cells from mice deficient in A2AR (Adora2a $a^{-/}$ mice) do not prevent disease ${ }^{148}$. Adoptive cell transfer of $\mathrm{T}_{\mathrm{Reg}}$ cells from wild-type mice, but not from Adora $2 a^{-/-}$ mice, also protected kidneys from ischaemiareperfusion injury ${ }^{56}$. In a similar $\mathrm{T}$ cell transfer model of graft-versus-host disease (GVHD), A2AR stimulation increased mouse survival, decreased production of pro-inflammatory cytokines (IL-6, TNF and IFN $\gamma$ ), increased production of anti-inflammatory cytokines
(TGF $\beta$ and IL-10) and increased $\mathrm{T}_{\text {Reg }}$ cell numbers in the periphery ${ }^{150}$. In a model of experimental glomerulonephritis, which is induced with glomerular basement membrane-specific antibodies, and in a model of lupus, A2AR activation protected kidneys by suppressing $\mathrm{T}$ cell infiltration and by favouring anti-inflammatory IL-4 and IL-10 production ${ }^{83,151}$.

Although A2AR signalling is generally considered to be anti-inflammatory, activation of A2ARs in the choroid plexus enhances lymphocyte entry into the brain and promotes $\mathrm{EAE}^{152}$. In another study, A2AR activation during the $T$ cell expansion phase of EAE enhanced $\mathrm{T}_{\mathrm{H}} 17$ cell responses owing to activation of $\gamma \delta \mathrm{T}$ cells ${ }^{153-155}$. Consequently, the onset of EAE was slowed in Adora $2 a^{-1-}$ mice, and A2AR blockade was protective ${ }^{152,156}$. However, selective A2AR deletion from haematopoietic cells enhanced the severity of $\mathrm{EAE}^{156}$. These findings suggest that, contrary to the anti-inflammatory effects of A2AR activation that have been noted in peripheral tissues, A2AR agonists should be used cautiously in cases of central nervous system (CNS) inflammation. The effects of A2BR signalling on autoimmune responses also are mixed. Although acutely anti-inflammatory, A2BR signalling enhances the expression of IL- 6 and $\mathrm{T}_{\mathrm{H}}$ 17-type cytokines. Hence, EAE is alleviated by A2BR deletion or blockade ${ }^{157}$.

In general, A2AR agonists (except in the CNS) and $\mathrm{P} 2$ purinergic receptor antagonists are potentially useful for the treatment of autoimmune diseases. In the case of A2BR, antagonists may be useful for suppressing long-term inflammatory responses.

\section{Purinergic signalling in cancer}

In the inflamed and hypoxic environment of solid tumours, both ATP and adenosine may remain elevated for extended periods of time. As a result, ATP and adenosine signal through ATP and adenosine receptors on tumour cells and tumour-associated immune cells, including macrophages and T cells (FIG. 6). A2AR signalling reduces the cytotoxic activity of $\mathrm{CD}^{+} \mathrm{T}$ cells and NK cells ${ }^{158-160}$ while increasing the numbers of immunosuppressive and pro-angiogenic cells - that is, $\mathrm{T}_{\mathrm{Reg}}$ cells and myeloid-derived suppressor cells (MDSCs) - that facilitate tumour growth ${ }^{161}$. Reducing adenosine production by deleting or blocking CD73 has been found in some cases to activate tumour-associated $\mathrm{T}$ cells, reduce tumour growth and invasiveness, and increase the effectiveness of antitumour vaccines ${ }^{158,162-164}$. However, B16-F10 melanoma growth and metastatic spreading was found to be insensitive to CD73 deletion ${ }^{165}$. The expression of CD39 and CD73 on the surface of cells in the tumour microenvironment is not limited to $\mathrm{T}_{\mathrm{Reg}}$ cells. In mice, these enzymes are expressed by several types of cancer cells ${ }^{166-170}$ (in fibrosarcoma, colon, triple negative breast, melanoma, brain, mastocytoma and lymphoma), by the exosomes produced by these cells, as well as by epithelial cells, endothelial venules and multipotent mesenchymal stromal cells. CD73 expression on triple negative breast cancer cells is associated with poor clinical outcomes and increased resistance to anthracycline chemotherapy ${ }^{171}$. Similarly to CD73 inhibition, 

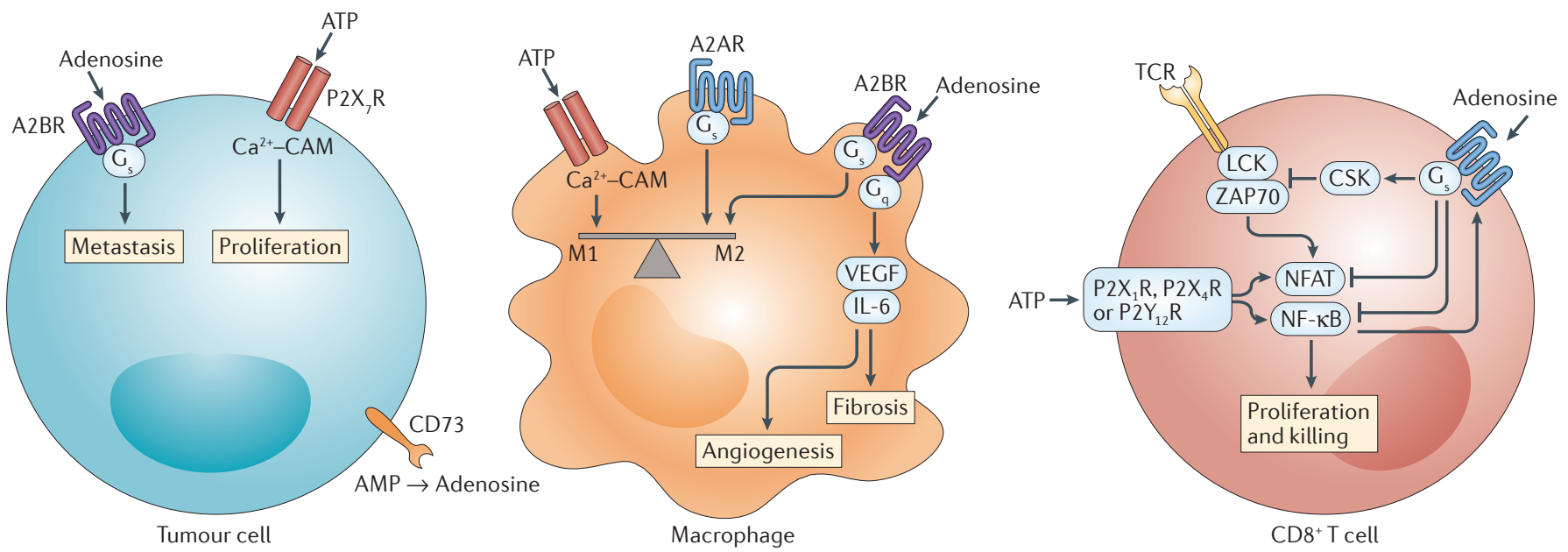

Figure 6 | Purinergic signalling in the tumour microenvironment. The solid tumour microenvironment is persistently inflamed and hypoxic and has high levels of ATP and adenosine. Most tumour cell express high levels of $\mathrm{P}_{2} \mathrm{X}_{7}$ purinergic receptors ( $\mathrm{P} 2 \mathrm{X}_{7} \mathrm{Rs}$ ), which stimulate cell proliferation, and of $\mathrm{A} 2 \mathrm{~B}$ adenosine receptors (A2BRs) that stimulate cell dispersal and metastasis. Myeloid lineage cells such as macrophages and dendritic cells are influenced by ATP binding to P2X $\mathrm{X}_{7}$ to adopt a pro-inflammatory (M1) phenotype. Myeloid cells are influenced by adenosine binding to A2ARs and A2BRs to adopt an anti-inflammatory (M2) phenotype that inhibits immune killing of tumours. A2BR signalling also enhances tumour angiogenesis and fibrosis. Cytotoxic $C D 8^{+} T$ cell proliferation and killing ability in response to T cell receptor (TCR) activation is enhanced by $P 2 X_{1} R, P 2 X_{4} R$ and $P 2 Y_{12} R$ signalling and inhibited by $A 2 A R$ signalling. $C A M$, calmodulin;

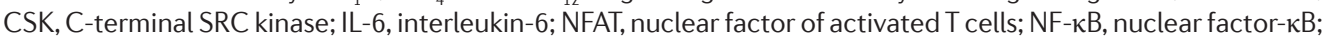
VEGF, vascular endothelial growth factor.

adenosine formation also is reduced by increasing oxygen delivery to ischaemic tissues. Supplemental oxygenation was found to reduce hypoxia-induced adenosine production in lung tumours, activate NK cells and $\mathrm{T}$ cells and reduce lung colonization by tumours ${ }^{159}$.

A2AR blockade in tumours. A2AR deletion or blockade was found to slow or eliminate tumour growth and activate tumour-infiltrating T cells ${ }^{172}$. Similar findings in several syngeneic tumour models have stimulated great interest in targeting A2ARs for cancer immunotherapy ${ }^{161}$. Macrophages, DCs and other myeloid cells also are targets of A2AR-mediated immunosuppression in tumours ${ }^{81,158,159}$. Selective deletion of A2ARs on myeloid cells was found to inhibit solid tumour growth and lung colonization by tumour cells and markedly reduce IL-10 production by tumour-associated DCs, macrophages and MDSCs, while indirectly increasing antigen-specific $\mathrm{CD}^{+} \mathrm{T}$ cell and NK cell activation ${ }^{81}$.

Despite the generally immunosuppressive effects of adenosine, A2AR blockade or deletion enhances tumour growth in some instances. For example, selective deletion of A2ARs from T cells markedly increased the growth of melanomas ${ }^{173}$. Although A2AR deletion acutely increases TCR signal strength and T cell activation, it also causes $T$ cell exhaustion and suppresses the expression of IL-7R that is needed for T cell survival ${ }^{173}$ (FIG. 2a). Exhausted cells collected from tumours have impaired IFN $\gamma$ production upon restimulation (C. C. and J. L., unpublished observations). T cells lacking A2ARs resemble T cells with high-avidity TCRs for the melanoma-expressed antigen transient receptor protein 2 (TRP2, also known as TRPC2), in that they only transiently inhibit melanoma growth before becoming exhausted ${ }^{174}$. By contrast, T cells with low-avidity TCRs do not become exhausted ${ }^{174,175}$. Despite their exhausted state, adoptively transferred A2AR-deficient $T$ cells are more effective than wildtype cells at producing a transient decrease in tumour growth. This suggests that A2AR deletion increases acute cytotoxicity, but this initial beneficial effect can be compromised by long-term $\mathrm{T}$ cell apoptosis and exhaustion. Therefore, A2AR blockade to stimulate high TCR signal intensity has the potential to produce beneficial therapeutic outcomes but may require careful dose optimization to control for activation-induced exhaustion and cell death. Optimal therapy may depend on engineering T cells to maintain their cytotoxicity and ability to survive during strong activation.

A2BRs in tumours. Adenosine binding to A2BRs found on most tumour cells enhances their metastatic capacity ${ }^{176}$. Hence, blockade of tumour A2BRs can blunt metastases. A2BR signalling also contributes to immunosuppression in tumours. In a model of bladder cancer, inhibition of tumour growth by the non-selective adenosine receptor antagonist theophylline was mediated by A2BR blockade but not by A2AR blockade ${ }^{107}$.

P2 purinergic receptors in tumours. Solid tumours have been found to contain high levels of ATP that engages $\mathrm{P} 2$ purinergic receptors on most immune cells, including $\mathrm{P} 2 \mathrm{X}_{7}$ Rs on macrophages and DCs that drive secretion of IL- $1 \beta$, which is required for polarization of IFN $\gamma$ producing $\mathrm{CD}^{+} \mathrm{T}$ cells ${ }^{78}$. In $\mathrm{P} 2 \mathrm{X}_{7} \mathrm{R}$-deficient mice, tumour growth and metastatic spreading are accelerated, intratumoural IL- $1 \beta$ and VEGF release are drastically 
reduced, and inflammatory cell infiltration is abrogated. DCs from $\mathrm{P}_{2} \mathrm{X}_{7} \mathrm{R}$-deficient mice are unresponsive to stimulation with tumour cells, and chemotaxis of $\mathrm{P} 2 \mathrm{X}_{7} \mathrm{R}$-deficient cells is impaired ${ }^{177}$. However, blockade of $\mathrm{P}_{2} \mathrm{X}_{7} \mathrm{Rs}$ on tumour cells inhibits their growth ${ }^{178}$. Hence, $\mathrm{P} 2 \mathrm{X}_{7} \mathrm{R}$ activation has opposing effects to directly promote tumour growth and to enhance immune killing of tumour cells. Non-small cell lung cancers harbouring chromosomal rearrangements of $A L K$ (anaplastic lymphoma kinase) are treated with ALK inhibitors, including crizotinib ${ }^{179}$. The expression by tumour cells of $\mathrm{G}_{\mathrm{q}}$ protein-coupled $\mathrm{P} 2 \mathrm{YRs}\left(\mathrm{P} 2 \mathrm{Y}_{1} \mathrm{R}, \mathrm{P}_{2} \mathrm{Y}_{2} \mathrm{R}\right.$ and $\mathrm{P} 2 \mathrm{Y}_{6} \mathrm{R}$ ) confers resistance to ALK inhibitors, in part through a PKC-dependent mechanism ${ }^{180}$. These findings suggest that certain P2YR inhibitors may overcome resistance to ALK-dependent non-small cell lung cancers. However, it is also possible that such compounds will reduce rejection of immunogenic tumours by reducing the activity of immune cells.

\section{Perspective}

In this Review, we have discussed the prominent role that purines have in shaping the evolution of immune cell responses to injury, infection, autoimmunity and cancer. ATP and other nucleotides are rapidly released into the extracellular space in response to tissue injury and are generally chemotactic and activating to immune cells. Extracellular adenosine levels rise more slowly and act on upregulated A2ARs and A2BRs on immune cells to limit the extent and duration of inflammation. Drugs that target purinergic receptors have great potential as therapeutic agents to treat inflammation, autoimmunity or cancer. At present, only a few drugs that target purinergic receptors have been approved, but many more are in clinical development. $\mathrm{P}_{2} \mathrm{X}_{7} \mathrm{R}$ antagonists are being evaluated in preclinical models of autoimmune diseases $^{144,145}$ and tissue transplantation ${ }^{11}$. Clopidogrel and other $\mathrm{P} 2 \mathrm{Y}_{12} \mathrm{R}$ antagonists that are clinically used to block platelet aggregation may have additional antiinflammatory uses by blocking $\mathrm{P} 2 \mathrm{Y}_{12}$ Rs on leukocytes. A2BR blockers seem to have acute anti-inflammatory effects but are potentially useful for the long-term treatment of fibrotic diseases and heart failure.

Adenosine has been found to have an important role in limiting ischaemia-reperfusion injury by suppressing the activation of iNKT cells. A2AR agonists inhibit the activation of iNKT cell as well as other immune cells and have potential for treating ischaemia-reperfusion injury, such as that seen in myocardial infarction and tissue transplantation. A2AR agonists also have promise for the treatment of inflammatory flares in autoimmune diseases. Similarly to A2AR agonists, therapeutic antibodies that selectively deplete iNKT cells may be useful to prevent tissue inflammation in response to vasoocclusive episodes or organ transplantation. A2AR agonists also are potentially useful for the treatment of chronic inflammatory diseases. For long-term therapy, it may be necessary to learn how to effectively apply intermittent A2AR agonist treatment to avoid desensitization while maintaining therapeutic efficacy.

Growing evidence indicates that A2AR and A2BR signalling in tumours contributes to the highly immunosuppressive tumour microenvironment. Several pharmaceutical companies are evaluating blockers of CD73 or A2ARs as exciting new cancer immunotherapeutic agents. This Review touched on three interesting recent developments regarding this approach. First, it is evident that the deletion or blockade of A2ARs on T cells activates these cells. However, activation-induced $\mathrm{T}$ cell exhaustion or death has been observed in some instances and underscores the point that adenosine receptor blockade and possibly other modes of $\mathrm{T}$ cell activation have the potential to kill $\mathrm{T}$ cells and consequently suppress the long-term immune response. This will be an important concept to consider as combinations of approaches to strongly activate tumour-associated T cells are investigated. Second, emerging evidence suggests a surprisingly important role for antigen-presenting cells as targets of adenosine receptor blockade in cancer. Myeloid selective deletion of A2ARs has been found in some mouse cancer models to be more effective at reducing tumour growth than global or lymphoid-selective A2AR deletion. It seems that the indirect activation of $\mathrm{T}$ cells through blockade of A2AR signalling in antigen-presenting cells may be more effective in stimulating antitumour immune responses that the direct activation of $\mathrm{T}$ cells. Third, and related to the second point, is the somewhat surprising observation that A2BR blockade is very effective at slowing tumour growth. Given the fact that there is much higher expression of A2BRs by myeloid cells than by lymphoid cells, this is consistent with the idea that antigen-presenting cells are underappreciated cellular targets of adenosine receptor blockade for cancer immunotherapy. One other point about the targeting of A2ARs versus A2BRs for immunotherapy relates to their relative affinities for adenosine. Although the functional potency of adenosine varies among different cells owing to variable numbers of spare receptors, in general adenosine activates A2AR responses at 10-100 times lower concentrations than are necessary to activate A2BR responses. As adenosine levels are high in solid tumours, lower levels of antagonist should be required to competitively inhibit adenosine binding to A2BRs than to A2ARs without the need to use excessively high concentrations that may produce adverse systemic side effects. As most studies of adenosine receptor blockers for cancer immunotherapy have focused on A2AR selective compounds, it will be of interest to further investigate selective A2BR blockers or compounds that block both A2ARs and A2BRs.
1. Kumar, A., Sharma, R., Kamaluddin. Formamidebased synthesis of nucleobases by metal(II) octacyanomolybdate(IV): implication in prebiotic chemistry. Astrobiology 14, 769-779 (2014).

2. Verkhratsky, A. \& Burnstock, G. Biology of purinergic signalling: its ancient evolutionary roots, its omnipresence and its multiple functional significance. Bioessays 36, 697-705 (2014) This article reviews the early evolution of purinerelease mechanisms, ATP-degrading enzymes and early purinergic receptors in bacteria, protozoa and algae.
3. Surprenant, A. $\&$ North, R. A. Signaling at purinergic P2X receptors. Annu. Rev. Physiol. 71, 333-359 (2009).

This article describes the trimeric structure of P2XRs and the parts involved in ATP binding, ion permeability and membrane trafficking. 
4. Jacobson, K. A. Structure-based approaches to ligands for G-protein-coupled adenosine and P2Y receptors, from small molecules to nanoconjugates. J. Med. Chem. 56, 3749-3767 (2013).

5. Chekeni, F. B. et al. Pannexin 1 channels mediate 'find-me' signal release and membrane permeability during apoptosis. Nature 467, 863-867 (2010). This report identifies ATP and UTP as 'find-me' signals released from pannexin 1 channels in apoptotic cells that attract phagocytes.

6. Pelegrin, P. \& Surprenant, A. The $\mathrm{P}_{2} \mathrm{X}_{7}$ receptorpannexin connection to dye uptake and IL-1 $\beta$ release. Purinergic Signal. 5, 129-137 (2009).

7. Poon, I. K. et al. Unexpected link between an antibiotic, pannexin channels and apoptosis. Nature 507, 329-334 (2014).

8. Shatarat, A., Dunn, W. R. \& Ralevic, V. Raised tone reveals ATP as a sympathetic neurotransmitter in the porcine mesenteric arterial bed. Purinergic Signal. 10 639-649 (2014)

9. Falker, K., Lange, D. \& Presek, P. P2Y12 ADP receptordependent tyrosine phosphorylation of proteins of 27 and $31 \mathrm{kDa}$ in thrombin-stimulated human platelets. Thromb. Haemostasis 93, 880-888 (2005).

10. Gao, Z G. Wei, O Jayasekara, M. P. \& Jacobson, K. A. The role of $\mathrm{P} 2 \mathrm{Y}$, and other $\mathrm{P} 2 \mathrm{Y}$ receptors in degranulation of human LAD2 mast cells. Purinergic Signal. 9, 31-40 (2013).

11. Asgari, E. et al. C3a modulates IL-1 $\beta$ secretion in human monocytes by regulating ATP efflux and subsequent NLRP3 inflammasome activation. Blood 122, 3473-3481 (2013) This report identifies the anaphylatoxin $\mathrm{C} 3 \mathrm{a}$ as a controller of ATP release that regulates IL-1 $\beta$ production in monocytes.

12. Ayna, G. et al. ATP release from dying autophagic cells and their phagocytosis are crucial for inflammasome activation in macrophages. PIOS ONE 7, e40069 (2012).

13. Junger, W. G. Immune cell regulation by autocrine purinergic signalling. Nat. Rev. Immunol. 11, 201-212 (2011).

14. Horenstein, A. L. et al. A CD38/CD203a/CD73 ectoenzymatic pathway independent of CD39 drives anovel adenosinergic loop in human T lymphocytes. Oncoimmunology 2, e26246 (2013).

This study shows that NAD ${ }^{+}$in the extracellular space can be converted to ADP-ribose by CD38 and that $\mathrm{NAD}^{+}$and ADP-ribose can be converted to AMP by ENPP 1

15. Langer, D. et al. Distribution of ectonucleotidases in the rodent brain revisited. Cell Tissue Res. 334, 199-217 (2008)

16. Jin, X., Shepherd, R. K., Duling, B. R. \& Linden, J. Inosine binds to $A 3$ adenosine receptors and stimulates mast cell degranulation. J. Clin. Invest. 100, 2849-2857 (1997).

This study shows that inosine is a weak agonist of rodent, but not human, A3Rs and stimulates rodent mast cell degranulation.

17. Baldwin, S. A. et al. The equilibrative nucleoside transporter family, SLC29. Pflugers Archiv. 447, 735-743 (2004)

18. Gray, J. H., Owen, R. P. \& Giacomini, K. M. The concentrative nucleoside transporter family, SLC28. Pflugers Archiv. 447, 728-734 (2004).

19. Eltzschig, H. K. et al. Central role of Sp 1-regulated CD39 in hypoxia/ischemia protection. Blood 113 224-232 (2009)

This report shows that hypoxia upregulates CD39 by activating the transcription factor SP1.

20. Diaz-Hernandez, M. et al. Inhibition of the ATP-gated P2X7 receptor promotes axonal growth and branching in cultured hippocampal neurons. J. Cell Sci. 121, 3717-3728 (2008).

21. Bele, T. \& Fabbretti, E. P2X receptors, sensory neurons and pain. Curr. Med. Chem. 22, 845-850 (2015).

22. Zimmermann, H. Extracellular ATP and other nucleotides-ubiquitous triggers of intercellular messenger release. Purinergic Signal. http://dx.doi.org/ 10.1007/s11302-015-9483-2 (2015)

23. Sandilos, J. K. et al. Pannexin 1, an ATP release channel, is activated by caspase cleavage of its poreassociated C-terminal autoinhibitory region. J. Biol. Chem. 287, 11303-11311 (2011). This report shows that pannexin 1 is activated by caspase-mediated cleavage of its pore-associated C-terminal autoinhibitory region.

24. Haas, M., Shaaban, A. \& Reiser, G. Alanine-(87)threonine polymorphism impairs signaling and internalization of the human $\mathrm{P} 2 \mathrm{Y}_{11}$ receptor, when
Co-expressed with the P2Y, receptor J. Neurochem. 129, 602-613 (2014)

25. Chen, Y. et al. ATP release guides neutrophi chemotaxis via $\mathrm{P} 2 \mathrm{Y} 2$ and $\mathrm{A} 3$ receptors. Science 314 1792-1795 (2006).

This article shows that $P 2 Y{ }_{2} R$ and A3R signalling controls purine gradient sensing and migration of neutrophils.

26. Barrett, M. O. et al. A selective high-affinity antagonis of the $\mathrm{P} 2 \mathrm{Y}_{14}$ receptor inhibits UDP-glucose-stimulated chemotaxis of human neutrophils. Mol. Pharmacol. 84, 41-49 (2013)

27. Ohta, A. \& Sitkovsky, M. Role of G-protein-coupled adenosine receptors in downregulation of inflammation and protection from tissue damage. Nature 414, 916-920 (2001).

28. Eckle, T. et al. Identification of hypoxia-inducible factor HIF-1A as transcriptional regulator of the A2B adenosine receptor during acute lung injury. J. Immunol. 192, 1249-1256 (2014).

This article shows that deletion of adenosine A2ARs enhances hepatic and systemic inflammatory responses.

29. Linden, J., Thai, T., Figler, H., Jin, X. \& Robeva, A. S. Characterization of human $\mathrm{A}_{2 \mathrm{~B}}$ adenosine receptors: radioligand binding, western blotting, and coupling to $\mathrm{G}_{\mathrm{q}}$ in human embryonic kidney 293 cells and HMC-1 mast cells. Mol. Pharmacol. 56, 705-713 (1999). This paper shows that A2BRs are dually coupled to $\mathrm{G}_{\mathrm{s}}$ and $\mathrm{G}_{\mathrm{q}}$-proteins and can elevate cAMP and $\mathrm{Ca}^{2+}$ levels.

30. Sorrentino, C., Miele, L., Porta, A., Pinto, A. \& Morello, S. Myeloid-derived suppressor cells contribute to A2B adenosine receptor-induced VEGF production and angiogenesis in a mouse melanoma model. Oncotarget 6, 27478-27489 (2015).

31. Zhou, Y. et al. Distinct roles for the $A_{2 B}$ adenosine receptor in acute and chronic stages of bleomycininduced lung injury. J. Immunol. 186, 1097-1106 (2011)

32. Wilson, J. M. et al. The $A_{2 B}$ adenosine receptor promotes Th17 differentiation via stimulation of dendritic cell IL-6. J. Immunol. 186, 6746-6752 (2011)

33. Resta, R. et al. Insights into thymic purine metabolism and adenosine deaminase deficiency revealed by transgenic mice overexpressing ecto-5'-nucleotidase (CD73). J. Clin. Invest. 99, 676-683 (1997).

34. Lepine, S., Le Stunff, H., Lakatos, B., Sulpice, J. C. \& Giraud, F. ATP-induced apoptosis of thymocytes is mediated by activation of $\mathrm{P} 2 \mathrm{X} 7$ receptor and involves de novo ceramide synthesis and mitochondria. Biochim. Biophys. Acta 1761, 73-82 (2006).

35. Cekic, C., Sag, D., Day, Y. J. \& Linden, J. Extracellular adenosine regulates naive $T$ cell development and peripheral maintenance. J. Exp. Med. 210 2693-2706 (2013)

This paper shows that A2AR signalling inhibits TCR-induced activation of the PI3K-AKT pathway, thereby reducing IL-7Ra downregulation and naive T cell apoptosis.

36. Woehrle, T. et al. Pannexin-1 hemichannel-mediated ATP release together with $\mathrm{P} 2 \mathrm{X} 1$ and $\mathrm{P} 2 \mathrm{X} 4$ receptors regulate T-cell activation at the immune synapse. Blood 116, 3475-3484 (2010).

37. Wang, L., Jacobsen, S. E., Bengtsson, A. \& Erlinge, D. $\mathrm{P} 2$ receptor mRNA expression profiles in human lymphocytes, monocytes and CD34+ stem and progenitor cells. BMC Immunol. 5, 16 (2004).

38. Romio, M. et al. Extracellular purine metabolism and signaling of CD73-derived adenosine in murine TReg and Teff cells. Am. J. Physiol. Cell Physiol. 301 C530-C539 (2011)

39. Vang, T. et al. Activation of the $\mathrm{COOH}$-terminal Src kinase (Csk) by cAMP-dependent protein kinase inhibits signaling through the T cell receptor. J. Exp. Med. 193, 497-507 (2001) This paper shows that PKA inhibits signalling through the TCR by phosphorylating CSK.

40. Linnemann, $C$. et al. Adenosine regulates CD8 T-cell priming by inhibition of membrane-proximal T-cell receptor signalling. Immunology 128, e728-e737 (2009)

41. Raskovalova, T. et al. Inhibition of cytokine production and cytotoxic activity of human antimelanoma specific $\mathrm{CD}^{+}$and $\mathrm{CD}^{+}{ }^{+} \mathrm{T}$ lymphocytes by adenosine-protein kinase A type I signaling. Cancer Res. 67, 5949-5956 (2007).

42. Su, Y., Jackson, E. K. \& Gorelik, E. Receptor desensitization and blockade of the suppressive effects of prostaglandin $E_{2}$ and adenosine on the cytotoxic activity of human melanoma-infiltrating T lymphocytes. Cancer Immunol. Immunother. 60, 111-122 (2011).

43. Sullivan, G. W., Carper, H. T. \& Mandell, G. L. The specific type IV phosphodiesterase inhibitor rolipram combined with adenosine reduces tumor necrosis factor- $\alpha$-primed neutrophil oxidative activity. Int. J. Immunopharmacol. 17, 793-803 (1995).

44. Wittmann, M. \& Helliwell, P. S. Phosphodiesterase 4 inhibition in the treatment of psoriasis, psoriatic arthritis and other chronic inflammatory diseases. Dermatol. Ther. 3, 1-15 (2013).

45. Chimote, A. A. et al. Selective inhibition of KCa3.1 channels mediates adenosine regulation of the motility of human T cells. J. Immunol. 191, 6273-6280 (2013)

46. Zhang, H. et al. Adenosine acts through A2 receptors to inhibit IL-2-induced tyrosine phosphorylation of STAT5 in T lymphocytes: role of cyclic adenosine $3^{\prime}, 5^{\prime}$-monophosphate and phosphatases. J. Immunol. 173, 932-944 (2004).

47. Butler, J. J et al. Adenosine inhibits activationinduced T cell expression of CD2 and CD28 co-stimulatory molecules: role of interleukin- 2 and cyclic AMP signaling pathways. J. Cell. Biochem. 89, 975-991 (2003).

48. Parry, R. V., Harris, S. J. \& Ward, S. G. Fine tuning T lymphocytes: a role for the lipid phosphatase SHIP-1. Biochim. Biophys. Acta 1804, 592-597 (2010)

49. Palmer, D. C. \& Restifo, N. P. Suppressors of cytokine signaling (SOCS) in T cell differentiation, maturation, and function. Trends Immunol. 30, 592-602 (2009).

50. Raskovalova, T., Lokshin, A., Huang, X., Jackson, E. K. ¿ Gorelik, E. Adenosine-mediated inhibition of cytotoxic activity and cytokine production by IL-2 NKp46-activated NK cells: involvement of protein kinase A isozyme I (PKA I). Immunol. Res. 36, 91-99 (2007).

51. Deaglio, S. et al. Adenosine generation catalyzed by CD39 and CD73 expressed on regulatory T cells mediates immune suppression. J. Exp. Med. 204 1257-1265 (2007).

This report shows that immunosuppression by $\mathrm{T}_{\mathrm{Reg}}$ cells is mediated in part by their expression of CD39 and CD73.

52. Schenk, U. et al. ATP Inhibits the generation and function of regulatory $T$ cells through the activation of purinergic P2X receptors. Science signaling 4, ra 12 (2011)

This report shows that IL- 6 increases ATP synthesis and release by $T_{\text {Reg }}$ cells and stimulates their conversion to $\mathrm{T}_{\mathrm{H}} 17$ cells in vivo.

53. Piconese, S. et al. Mast cells counteract regulatory T-cell suppression through interleukin- 6 and OX40/ OX40 L axis toward Th17-cell differentiation. Blood 114, 2639-2648 (2009).

54. Rissiek, B., Haag, F., Boyer, O., Koch-Nolte, F. \& Adriouch, S. ADP-ribosylation of P2X7: a matter of life and death for regulatory $T$ cells and natural killer T cells. Curr. Top. Microbiol. Immunol. 384, 107-126 (2015)

This report shows that ADP-ribosylation activates rodent $P 2 X_{7} R s$ and stimulates apoptosis of $T_{\text {Reg }}$ cells and iNKT cells.

55. Ohta, A. \& Sitkovsky, M. Extracellular adenosinemediated modulation of regulatory T cells. Frontiers Immunol. 5, 304 (2014).

56. Kinsey, G. R. et al. Autocrine adenosine signaling promotes regulatory $\mathrm{T}$ cell-mediated renal protection. J. Am. Soc. Nephrol. 23, 1528-1537 (2012).

57. Smyth, L. A. et al. CD73 expression on extracellular vesicles derived from $\mathrm{CD} 4{ }^{+} \mathrm{CD} 25^{+}$Foxp3 ${ }^{+} \mathrm{T}$ cells contributes to their regulatory function. Eur. J. Immunol. 43, 2430-2440 (2013).

58. Saldanha-Araujo, F. et al. Mesenchymal stromal cells up-regulate CD39 and increase adenosine production to suppress activated T-lymphocytes. Stem Cell Res. 7 66-74 (2011).

59. Mandapathil, M., Lang, S., Gorelik, E. ¿ Whiteside, T. L. Isolation of functional human regulatory T cells (Treg) from the peripheral blood based on the CD39 expression. J. Immunol. Methods 346, 55-63 (2009).

60. Nikolova, M et al. CD39/adenosine pathway is involved in AIDS progression. PLoS Pathog. 7 e1002110 (2011) This report shows that HIV-1-positive patients have increased CD39 expression on $\mathrm{T}_{\mathrm{Reg}}$ cells and that a CD39 gene polymorphism is associated with reduced CD39 expression and a slower progression to AIDS 
61. Borsellino, G. et al. Expression of ectonucleotidase CD39 by Foxp3+ TReg cells: hydrolysis of extracellular ATP and immune suppression. Blood 110, 1225-1232 (2007).

62. Dwyer, K. M. et al. Expression of CD39 by human peripheral blood $\mathrm{CD} 4{ }^{+} \mathrm{CD} 25^{+} \mathrm{T}$ cells denotes a regulatory memory phenotype. Am. J. Transplant. 10, 2410-2420 (2010)

63. Jenabian, M. A. et al. Regulatory T cells negatively affect IL-2 production of effector T cells through CD39/ adenosine pathway in HIV infection. PLoS Pathog. 9 , e 1003319 (2013)

64. Reilly, E. C., Wands, J. R. \& Brossay, L. Cytokine dependent and independent iNKT cell activation. Cytokine 51, 227-231 (2010)

65. Araki, M., Miyake, S. \& Yamamura, T. Synthetic glycolipid ligands for human iNKT cells as potential therapeutic agents for immunotherapy. Curr. Med. Chem. 15, 2337-2345 (2008).

66. Beldi, G. et al. Natural killer T cell dysfunction in CD39-null mice protects against concanavalin A-induced hepatitis. Hepatology 48, 841-852 (2008).

This paper demonstrates that deletion of CD39 elevates ATP levels in the inflamed liver and causes P2X $\mathrm{X}_{7}$ R-mediated apoptosis of iNKT cells.

67. Lappas, C. M., Day, Y. J., Marshall, M. A., Engelhard, V. H. \& Linden, J. Adenosine A2A receptor activation reduces hepatic ischemia reperfusion injury by inhibiting CD1d-dependent NKT cell activation. J. Exp. Med. 203, 2639-2648 (2006). This paper shows that adenosine protects liver from ischaemia-reperfusion injury by activating A2ARs on iNKT cells.

68. Linden, J. \& Cekic, C. Regulation of lymphocyte function by adenosine. Arterioscler. Thromb. Vasc. Biol. 32, 2097-2103 (2012).

69. Nowak-Machen, M. et al. Pulmonary natural killer $\mathrm{T}$ cells play an essential role in mediating hyperoxic acute lung injury. Am. J. Respir. Cell Mol. Biol. 48 601-609 (2013)

70. Brennan, P. J. et al. Activation of iNKT cells by a distinct constituent of the endogenous glucosylceramide fraction. Proc. Natl Acad. Sci. USA 111, 13433-13438 (2014)

71. Wallace, K. L. et al. NKT cells mediate pulmonary inflammation and dysfunction in murine sickle cell disease through production of IFN- $\gamma$ and CXCR3 chemokines. Blood 114, 667-676 (2009).

72. Uzar, E. et al. The activity of adenosine deaminase and the level of nitric oxide in spinal cord of methotrexate administered rats: protective effect of caffeic acid phenethyl ester. Toxicology $\mathbf{2 1 8}$ 125-133 (2006)

73. Nowak, M. et al. The A2aR adenosine receptor controls cytokine production in iNKT cells. Eur. J. Immunol. 40, 682-687 (2010).

74. Cao, Z. et al. Preactivation of NKT cells with $\alpha$-GalCer protects against hepatic ischemia-reperfusion injury in mouse by a mechanism involving IL-13 and adenosine A2A receptor. Am. J. Physiol. Gastrointest. Liver Physiol. 297, G249-G258 (2009).

75. Wallace, K. L. \& Linden, J. Adenosine A2A receptors induced on iNKT and NK cells reduce pulmonary inflammation and injury in mice with sickle cell disease. Blood 116, 5010-5020 (2010). This study shows that activation of A2ARs inhibits activation of iNKT cells in mouse and human sickle cell disease.

76. Field, J. J. et al. Sickle cell vaso-occlusion causes activation of iNKT cells that is decreased by the adenosine $\mathrm{A} 2 \mathrm{~A}$ receptor agonist regadenoson. Blood 121, 3329-3334 (2013)

77. Elliott, M. R. et al. Nucleotides released by apoptotic cells act as a find-me signal to promote phagocytic clearance. Nature 461, 282-286 (2009).

78. Aymeric, L. et al. Tumor cell death and ATP release prime dendritic cells and efficient anticancer immunity. Cancer Res. 70, 855-858 (2010).

This study shows that ATP released from tumour cells in response to chemotherapy activates purinergic $P 2 X_{7}$ Rs on DCs and stimulates their secretion of IL- $1 \beta$.

79. Gessi, S. et al. Adenosine modulates HIF- $1 \alpha$, VEGF, IL-8, and foam cell formation in a human model of hypoxic foam cells. Arterioscler. Thromb. Vasc. Biol. 30, 90-97 (2010)

80. Ryzhov, S. et al. Effect of A2B adenosine receptor gene ablation on adenosine-dependent regulation of proinflammatory cytokines. J. Pharmacol. Exp. Ther 324, 694-700 (2008)
81. Cekic, C., Day, Y. J., Sag, D. \& Linden, J. Myeloid expression of adenosine A2A receptor suppresses $\mathrm{T}$ and NK cell responses in the solid tumor microenvironment. Cancer Res. 74, 7250-7259 (2014).

This study shows that myeloid selective deletion of A2ARs slows tumour growth owing to indirect activation of $\mathrm{T}$ cells.

82. Ferrante, C. J. et al. The adenosine-dependent angiogenic switch of macrophages to an M2-like phenotype is independent of interleukin-4 receptor $\alpha$ (IL-4R $\alpha$ ) signaling. Inflammation 36, 921-931 (2013)

83. Garcia, G. E. et al. Adenosine A2A receptor activation and macrophage-mediated experimental glomerulonephritis. FASEB J. 22, 445-454 (2008).

84. Majumdar, S. \& Aggarwal, B. B. Adenosine suppresses activation of nuclear factor- $\mathrm{\kappa B}$ selectively induced by tumor necrosis factor in different cell types. Oncogene 22, 1206-1218 (2003)

85. Fotheringham, J., Mayne, M., Holden, C., Nath, A. \& Geiger, J. D. Adenosine receptors control HIV-1 Tatinduced inflammatory responses through protein phosphatase. Virology 327, 186-195 (2004).

86. Elson, G. et al. Induction of murine adenosine $A_{2 A}$ receptor expression by LPS: analysis of the $5^{\circ}$ upstream promoter. Genes Immun. 14, 147-153 (2013).

87. He, X. et al. A feedback loop in PPAR $\gamma$-adenosine A2A receptor signaling inhibits inflammation and attenuates lung damages in a mouse model of LPS induced acute lung injury. Cell Signal. 25, 1913-1923 (2013).

88. Murphree, L. J., Sullivan, G. W., Marshall, M. A. \& Linden, J. Lipopolysaccharide rapidly modifies adenosine receptor transcripts in murine and human macrophages: role of NF- $\mathrm{kB}$ in $\mathrm{A}_{2 \mathrm{~A}}$ adenosine receptor induction. Biochem. J. 391, 575-580 (2005)

89. Heyn, J. et al. Adenosine A2A receptor upregulation in human PMNs is controlled by miRNA-214, miRNA-15, and miRNA-16. Shock 37, 156-163 (2012).

90. Duro, E., Pallai, A., Koroskenyi, K., Sarang, Z. \& Szondy, Z. Adenosine A3 receptors negatively regulate the engulfment-dependent apoptotic cell suppression of inflammation. Immunol. Lett. 162, 292-301 (2014)

91. Li, L. et al. Dendritic cells tolerized with adenosine $\mathrm{A}_{2} \mathrm{AR}$ agonist attenuate acute kidney injury. J. Clin. Invest. 122, 3931-3942 (2012).

This report shows that ex vivo A2AR-induced tolerization of DCs before adoptive cell transfer suppresses NKT cell activation and renal ischaemia-reperfusion injury.

92. Liu, C. et al. Adenosine A2A receptor, a potential valuable target for controlling reoxygenated $D C s$ triggered inflammation. Mol. Immunol. 63, 559-565 (2015).

93. Panther, E. et al. Adenosine affects expression of membrane molecules, cytokine and chemokine release, and the T-cell stimulatory capacity of human dendritic cells. Blood 101, 3985-3990 (2003).

94. Ring, S. et al. Regulatory T cell-derived adenosine induces dendritic cell migration through the Epac-Rap1 pathway. J. Immunol. 194, 3735-3744 (2015).

95. Hofer, S. et al. Adenosine slows migration of dendritic cells but does not affect other aspects of dendritic cell maturation. J. Investigative Dermatol. 121, 300-307 (2003).

96. Panther, E. et al. Expression and function of adenosine receptors in human dendritic cells. FASEB J. 15 1963-1970 (2001)

97. Schnurr, M. et al. Role of adenosine receptors in regulating chemotaxis and cytokine production of plasmacytoid dendritic cells. Blood 103, 1391-1397 (2004).

98. Novitskiy, S. V. et al. Adenosine receptors in regulation of dendritic cell differentiation and function. Blood 112, 1822-1831 (2008)

This report shows that adenosine signalling through A2BRs stimulates DC polarization to tolerogenic, angiogenic and IL-6 producing cells.

99. Ben Addi, A. et al. Modulation of murine dendritic cell function by adenine nucleotides and adenosine: involvement of the $\mathrm{A}_{2 \mathrm{~B}}$ receptor. Eur. J. Immunol. 38 1610-1620 (2008)

100. Figueiredo, A. B., Serafim, T. D., Marques-da-Silva, E. A. Meyer-Fernandes, J. R. \& Afonso, L. C. Leishmania amazonensis impairs DC function by inhibiting CD40 expression via A2B adenosine receptor activation. Eur. J. Immunol. 42, 1203-1215 (2012).
101. Wilson, J M et al The A2B adenosine receptor impairs the maturation and immunogenicity of dendritic cells. J. Immunol. 182, 4616-4623 (2009)

102. Yang, M. et al. HIF-dependent induction of adenosine receptor $\mathrm{A} 2 \mathrm{~b}$ skews human dendritic cells to $\mathrm{a}$ Th2-stimulating phenotype under hypoxia. Immunol. Cell Biol. 88, 165-171 (2010).

103. Martin, M., Huguet, J., Centelles, J. J. \& Franco, R. Expression of ecto-adenosine deaminase and CD26 in human T cells triggered by the TCR-CD3 complex. Possible role of adenosine deaminase as costimulatory molecule. J. Immunol. 155, 4630-4643 (1995).

104. Martinez-Navio, J. M. et al. Adenosine deaminase potentiates the generation of effector, memory, and regulatory CD4+ T cells. J. Leukocyte Biol. 89, 127-136 (2011)

105. Pacheco, R. et al. CD26, adenosine deaminase, and adenosine receptors mediate costimulatory signals in the immunological synapse. Proc. Natl Acad. Sci. USA 102, 9583-9588 (2005).

This study shows that an interaction of ADA expressed on DCs with CD26 on human T cells enhances pro-inflammatory cytokine production.

106. Gilles, S. et al. Pollen metabolome analysis reveals adenosine as a major regulator of dendritic cellprimed $\mathrm{T}_{\mathrm{H}}$ cell responses. J. Allergy Clin. Immunol. 127, 454-461 (2011).

107. Cekic, C. et al. Adenosine A2B receptor blockade slows growth of bladder and breast tumors. J. Immunol. 188, 198-205 (2012).

This study shows that inhibition of bladder tumour growth by theophylline, a non-selective adenosine receptor antagonist, is mediated primarily by A2BR, and not by A2AR, blockade.

108. Inoue, Y., Chen, Y., Hirsh, M. I., Yip, L. \& Junger, W. G. $\mathrm{A} 3$ and $\mathrm{P} 2 \mathrm{Y} 2$ receptors control the recruitment of neutrophils to the lungs in a mouse model of sepsis. Shock 30, 173-177 (2008).

109. Moore, C. C. et al. An A2A adenosine receptor agonist, ATL313, reduces inflammation and improves survival in murine sepsis models. BMC Infect. Dis. 8, 141 (2008).

110. Griffin, G. K. et al. IL-17 and TNF- $\alpha$ sustain neutrophil recruitment during inflammation through synergistic effects on endothelial activation. J. Immunol. 188, 6287-6299 (2012)

111. Reutershan, J., Cagnina, R. E., Chang, D., Linden, J. $\&$ Ley, K. Therapeutic anti-inflammatory effects of myeloid cell adenosine receptor A2a stimulation in lipopolysaccharide-induced lung injury. J. Immunol. 179, 1254-1263 (2007).

112. Sullivan, G. W., Rieger, J. M., Scheld, W. M., Macdonald, T. L. \& Linden, J. Cyclic AMP-dependent inhibition of human neutrophil oxidative activity by substituted 2-propynylcyclohexyl adenosine $A$ receptor agonists. Br. J. Pharmacol. 132, 1017-1026 (2001)

113. Sullivan, G. W. et al. Activation of A2A adenosine receptors inhibits expression of $\alpha 4 / \beta 1$ integrin (very late antigen-4) on stimulated human neutrophils. J. Leukocyte Biol. 75, 127-134 (2004).

114. Roberts, V. S., Cowan, P. J., Alexander, S. I., Robson, S. C. \& Dwyer, K. M. The role of adenosine receptors $\mathrm{A} 2 \mathrm{~A}$ and $\mathrm{A} 2 \mathrm{~B}$ signaling in renal fibrosis. Kidney Int. 86, 685-692 (2014).

115. Zhang, H. et al. Blockade of A2B adenosine receptor reduces left ventricular dysfunction and ventricular arrhythmias 1 week after myocardial infarction in the rat model. Heart Rhythm. 11, 101-109 (2014). This report shows that blockade of A2BR signalling beginning 1 week after myocardial infarction reduces heart failure.

116. Wen, J. et al. Increased adenosine contributes to penile fibrosis, a dangerous feature of priapism, via A2B adenosine receptor signaling. FASEB J. 24 740-749 (2010).

117. Mizumura, T., Auchampach, J. A., Linden, J., Bruns, R. F. \& Gross, G. J. PD 81,723, an allosteric enhancer of the $\mathrm{A} 1$ adenosine receptor, lowers the threshold for ischemic preconditioning in dogs. Circ. Res. 79, 415-423 (1996). This report shows that allosteric enhancement of A1R signalling increases myocardial IPC

118. Maas, J. E., Wan, T. C., Figler, R. A., Gross, G. J. \& Auchampach, J. A. Evidence that the acute phase of ischemic preconditioning does not require signaling by the A 2B adenosine receptor. J. Mol. Cell. Cardiol. 49 886-893 (2010)

119. Yang, Z. et al. Infarct-sparing effect of A2A-adenosine receptor activation is due primarily to its action on lymphocytes. Circulation 111, 2190-2197 (2005). 
120. Yang, Z. et al. Myocardial infarct-sparing effect of adenosine $\mathrm{A} 2 \mathrm{~A}$ receptor activation is due to its action on CD4 ${ }^{+}$T lymphocytes. Circulation 114, 2056-2064 (2006).

121. Tian, Y., Marshall, M., French, B. A., Linden, J. \& Yang, $Z$. The infarct-sparing effect of IB-MECA against myocardial ischemia/reperfusion injury in mice is mediated by sequential activation of adenosine $\mathrm{A} 3$ and A 2A receptors. Bas. Res. Cardiol. 110, 16 (2015).

122. Micari, A. et al. Improvement in microvascular reflow and reduction of infarct size with adenosine in patients undergoing primary coronary stenting. Am. J. Cardiol. 96, 1410-1415 (2005)

123. Blume, C. et al. Autoimmunity in CD73/ Ecto-5'-nucleotidase deficient mice induces renal injury. PloS ONE 7, e37100 (2012).

124. Park, S. W. et al. A1 adenosine receptor allosteric enhancer PD-81723 protects against renal ischemiareperfusion injury. Am. J. Physiol. Renal Physiol. 303 F721-F732 (2012)

125. Kim, M. et al. Kidney-specific reconstitution of the A1 adenosine receptor in A1 adenosine receptor knockout mice reduces renal ischemia-reperfusion injury. Kidney Int. 75, 809-823 (2009).

126. Lee, H. T., Gallos, G., Nasr, S. H. \& Emala, C. W. $\mathrm{A} 1$ adenosine receptor activation inhibits inflammation, necrosis, and apoptosis after renal ischemia-reperfusion injury in mice. J. Am. Soc. Nephrol. 15, 102-111 (2004).

127. Garcia, G. E., Truong, L. D., Chen, J. F., Johnson, R. J. $\S$ Feng, L. Adenosine $A_{2 A}$ receptor activation prevents progressive kidney fibrosis in a model of immuneassociated chronic inflammation. Kidney Int. 80, 378-388 (2011)

128. Awad, A. S. et al. Adenosine A2A receptor activation attenuates inflammation and injury in diabetic nephropathy. Am. J. Physiol. Renal Physiol. 290 F828-F837 (2006)

129. Okusa, M. D., Linden, J., Macdonald, T. \& Huang, L. Selective A2A adenosine receptor activation reduces ischemia-reperfusion injury in rat kidney. Am. J. Physiol. 277, F404-F412 (1999).

130. Duhant, X. et al. Extracellular adenine nucleotides inhibit the activation of human CD4 ${ }^{+} \mathrm{T}$ lymphocytes. J. Immunol. 169, 15-21 (2002)

131. Grenz, A. et al. Adora2b adenosine receptor signaling protects during acute kidney injury via inhibition of neutrophil-dependent TNF- $\alpha$ release. J. Immunol. $189,4566-4573(2012)$

132. Grenz, A et al. The reno-vascular A2B adenosine receptor protects the kidney from ischemia. PLoS Med. 5, e137 (2008).

133. Joo, J. D. et al. Acute and delayed renal protection against renal ischemia and reperfusion injury with A1 adenosine receptors. Am. J. Physiol. Renal Physiol. 293, F1847-F1857 (2007)

134. Folkesson, H. G., Kuzenko, S. R., Lipson, D. A., Matthay, M. A. \& Simmons, M. A. The adenosine $2 A$ receptor agonist GW328267C improves lung function after acute lung injury in rats. Am. J. Physiol. Lung Cell. Mol. Physiol. 303, L259-L271 (2012).

135. Gazoni, L. M. et al. Activation of A1, A2A, or A3 adenosine receptors attenuates lung ischemiareperfusion injury. J. Thorac. Cardiovasc. Surg. 140, 440-446 (2010)

136. Schingnitz, U. et al. Signaling through the A2B adenosine receptor dampens endotoxin-induced acute lung injury. J. Immunol. 184, 5271-5279 (2010).

137. Ohta, A. et al. In vitro induction of T cells that are resistant to $\mathrm{A} 2$ adenosine receptor-mediated immunosuppression. Br. J. Pharmacol. 156 297-306 (2009)

138. Sharma, A. K. et al. Adenosine A2A receptor activation on $\mathrm{CD}_{4}{ }^{+} \mathrm{T}$ lymphocytes and neutrophils attenuates lung ischemia-reperfusion injury. J. Thorac Cardiovascular Surg. 139, 474-482 (2010)

139. Karmouty-Quintana, H. et al. Adenosine A2B receptor and hyaluronan modulate pulmonary hypertension associated with chronic obstructive pulmonary disease. Am. J. Respiratory Cell. Mol. Biol. 49, 1038-1047 (2013).

140. Belikoff, B. G., Vaickus, L. J., Sitkovsky, M. \& Remick, D. G. A2B adenosine receptor expression by myeloid cells is proinflammatory in murine allergicairway inflammation. J. Immunol. 189, 3707-3713 (2012).

141. Ryzhov, S., Goldstein, A. E., Biaggioni, I. \& Feoktistov, I. Cross-talk between $\mathrm{G}_{\mathrm{s}}$ - and $\mathrm{G}_{\mathrm{q}}$-coupled pathways in regulation of interleukin- 4 by $A_{2 B}$ adenosine receptors in human mast cells. Mol. Pharmacol. 70, 727-735 (2006).
142. Karmouty-Quintana, H. et al. Deletion of ADORA2B from myeloid cells dampens lung fibrosis and pulmonary hypertension. FASEB J. 29, 50-60 (2015). This article shows that deletion of A2BRs from myeloid cells reduces pulmonary fibrosis.

143. Le, T. T. et al. Blockade of IL-6 trans signaling attenuates pulmonary fibrosis. J. Immunol. 193 3755-3768 (2014)

144. Vergani, A. et al. Effect of the purinergic inhibitor oxidized ATP in a model of islet allograft rejection. Diabetes 62, 1665-1675 (2013)

145. Lang, P. A. et al. Oxidized ATP inhibits T-cell-mediated autoimmunity. Eur. J. Immunol. 40, 2401-2408 (2010).

146. Ohta, A. et al. The development and immunosuppressive functions of $\mathrm{CD} 4{ }^{+} \mathrm{CD} 25^{+} \mathrm{FoxP} 3+$ regulatory T cells are under influence of the adenosineA2A adenosine receptor pathway. Frontiers Immunol. 3, $190(2012)$

147. Kurtz, C. C. et al. Extracellular adenosine regulates colitis through effects on lymphoid and nonlymphoid cells. Am. J. Physiol. Gastrointest. Liver Physiol. 307 G338-G346 (2014)

148. Naganuma, M. et al. Cutting edge: critical role for A2A adenosine receptors in the T cell-mediated regulation of colitis. J. Immunol. 177, 2765-2769 (2006)

This article shows that deletion of A2ARs from $T_{\text {en }}$ cells inhibits their ability to prevent colitis.

149. Odashima, M. et al. Activation of A2A adenosine receptor attenuates intestinal inflammation in animal models of inflammatory bowel disease. Gastroenterology 129, 26-33 (2005)

150. Han, K. L. et al. Adenosine $A_{2} A$ receptor agonistmediated increase in donor-derived regulatory $T$ cells suppresses development of graft-versus-host disease. J. Immunol. 190, 458-468 (2013).

151. Zhang, L. et al. Adenosine $2 A$ receptor is protective against renal injury in MRL/lpr mice. Lupus 20 . 667-677 (2011).

152. Mills, J. H. et al. CD73 is required for efficient entry of lymphocytes into the central nervous system during experimental autoimmune encephalomyelitis. Proc. Natl Acad. Sci. USA 105, 9325-9330 (2008). This article shows that CD73 expression and A2AR signalling stimulate entry of lymphocytes into the CNS during EAE.

153. Liang, D. et al. Anti-inflammatory or proinflammatory effect of an adenosine receptor agonist on the Th17 autoimmune response is inflammatory environmentdependent. J. Immunol. 193, 5498-5505 (2014).

154. Liang, D. et al. Roles of the adenosine receptor and CD73 in the regulatory effect of $\gamma \delta$ T cells. PLoS ONE 9, e108932 (2014)

155. Lee, D. J. \& Taylor, A. W. Both MC5r and A2Ar are required for protective regulatory immunity in the spleen of post-experimental autoimmune uveitis in mice. J. Immunol. 191, 4103-4111 (2013).

156. Mills, J. H., Kim, D. G., Krenz, A., Chen, J. F. \& Bynoe, M. S. A2A adenosine receptor signaling in lymphocytes and the central nervous system regulates inflammation during experimental autoimmune encephalomyelitis. J. Immunol. 188, 5713-5722 (2012).

157. Wei, W. et al. Blocking A2B adenosine receptor alleviates pathogenesis of experimental autoimmune encephalomyelitis via inhibition of IL-6 production and Th1 7 differentiation. J. Immunol. 190, 138-146 (2013)

158. Beavis, P. A. et al. Blockade of A2A receptors potently suppresses the metastasis of $\mathrm{CD} 73$ + tumors. Proc. Natl Acad. Sci. USA 110, 14711-14716 (2013). This report shows that blockade of A2ARs prevents metastasis of tumours that express CD73.

159. Hatfield, S. M. et al. Immunological mechanisms of the antitumor effects of supplemental oxygenation. Sci. Transl Med. 7, 277 ra230 (2015) This report shows that respiratory hypoxia promotes the regression of spontaneous metastases from orthotopical breast tumours.

160. Mittal, D. et al. Antimetastatic effects of blocking PD-1 and the adenosine A2A receptor. Cancer Res. 74 , 3652-3658 (2014)

161. Leone, R. D., Lo, Y. C. \& Powell, J. D. A2aR antagonists: next generation checkpoint blockade for cancer immunotherapy. Comput. Struct. Biotechnol. J. 13, 265-272 (2015).

This article reviews evidence that blockade of A2ARs enhances antitumour effects of checkpoint inhibitors, tumour vaccines and adoptive $\mathrm{T}$ cell transfer.
162. Stagg, J. et al. Anti-CD73 antibody therapy inhibits breast tumor growth and metastasis. Proc. Natl Acad. Sci. USA 107, 1547-1552 (2010). This article shows that inhibition of CD73 inhibits growth and metastasis of orthotopic breast tumours.

163. Waickman, A. T. et al. Enhancement of tumor immunotherapy by deletion of the A2A adenosine receptor. Cancer Immunol. Immunother. 61, 917-926 (2012)

164. Beavis, P. A. et al. Adenosine receptor 2A blockade increases the efficacy of anti-pd-1 through enhanced antitumor t-cell responses. Cancer Immunol. Res. 3, 506-517 (2015)

165. Burghoff, S. et al. Growth and metastasis of B16-F10 melanoma cells is not critically dependent on host CD73 expression in mice. BMC Cancer 14, 898 (2014).

166. Amarnath, S. et al. Bone marrow-derived mesenchymal stromal cells harness purinergenic signaling to tolerize human Th1 cells in vivo. Stem Cells 33, 1200-1212 (2015).

167. Sattler, C. et al. Inhibition of T-cell proliferation by murine multipotent mesenchymal stromal cells is mediated by CD39 expression and adenosine generation. Cell Transplant. 20, 1221-1230 (2011).

168. Hausler, S. F. et al. Ectonucleotidases CD39 and CD73 on OvCA cells are potent adenosine-generating enzymes responsible for adenosine receptor $2 \mathrm{~A}$ dependent suppression of T cell function and NK cell cytotoxicity. Cancer Immunol. Immunother. 60, 1405-1418 (2011)

169. Takedachi, M. et al. CD73-generated adenosine restricts lymphocyte migration into draining lymph nodes. J. Immunol. 180, 6288-6296 (2008).

170. Clayton, A., Al-Taei, S., Webber, J., Mason, M. D. \& Tabi, Z. Cancer exosomes express CD39 and CD73. which suppress T cells through adenosine production. J. Immunol. 187, 676-683 (2011).

171. Allard, B., Turcotte, M. \& Stagg, J. Targeting CD73 and downstream adenosine receptor signaling in triple-negative breast cancer. Expert Opin. Ther. Targets 18, 863-881 (2014).

172. Ohta, A. et al. A2A adenosine receptor protects tumors from antitumor T cells. Proc. Natl Acad. SCi. USA 103, 13132-13137 (2006).

This article shows that deletion of A2ARs results in the rejection of highly immunogenic melanoma and activates T cells.

173. Cekic, C. \& Linden, J. Adenosine A2A receptors intrinsically regulate $\mathrm{CD} 8{ }^{+} \mathrm{T}$ cells in the tumor microenvironment. Cancer Res. 74, 7239-7249 (2014).

This report shows that $\mathrm{T}$ cell-specific deletion of A2ARs increases melanoma growth and reduces IL-7R expression in tumour-associated T cells.

174. Singh, V., Ji, Q., Feigenbaum, L., Leighty, R. M. \& Hurwitz, A. A. Melanoma progression despite infiltration by in vivo-primed TRP-2-specific T cells. J. Immunother. 32, 129-139 (2009).

175. Zhu, Z. et al. High-avidity T cells are preferentially tolerized in the tumor microenvironment. Cancer Res. 73, 595-604 (2013)

176. Ntantie, E. et al. An adenosine-mediated signaling pathway suppresses prenylation of the GTPase Rap1B and promotes cell scattering. Sci. Signal. 6, ra39 (2013). This report shows that activation of A2BRs on tumour cells promotes cell scattering and metastasis.

177. Adinolfi, E. et al. Accelerated tumor progression in mice lacking the ATP receptor P2X7. Cancer Res. 75 , 635-644 (2015) This report shows that deletion of $P 2 X_{7} R$ reduces the immune response to tumours and enhances tumour growth.

178. Di, V. irgilio F. Purines, purinergic receptors, and cancer. Cancer Res. 72, 5441-5447 (2012).

179. Awad, M. M. \& Shaw, A. T. ALK inhibitors in non-small cell lung cancer: crizotinib and beyond. Clin. Adv. Hematol. Oncol. 12, 429-439 (2014).

180. Wilson, F. H. et al. A functional landscape of resistance to ALK inhibition in lung cancer. Cancer Cell 27 397-408 (2015)

181. Martini, C. et al. A2 adenosine receptors in neutrophils from healthy volunteers and patients with rheumatic disease. Adv. Exp. Med. Biol. 309A, 459-462 (1991)

182. Varani, K., Gessi, S., Dalpiaz, A. \& Borea, P. A. Pharmacological and biochemical characterization of purified $\mathrm{A} 2 \mathrm{a}$ adenosine receptors in human platelet membranes by [3 $\left.{ }^{3}\right]$-CCS 21680 binding. Br. J. Pharmacol. 117, 1693-1701 (1996). 
183. Hasko, G., Linden, J., Cronstein, B. \& Pacher, P. Adenosine receptors: therapeutic aspects for inflammatory and immune diseases. Nat. Rev. Drug Discov. 7, 759-770 (2008)

184. Auchampach, J. A., Jin, X., Wan, T. C., Caughey, G. H. $\&$ Linden, J. Canine mast cell adenosine receptors: cloning and expression of the $\mathrm{A}_{3}$ receptor and evidence that degranulation is mediated by the $A_{2 B}$ receptor. Mol. Pharmacol. 52, 846-860 (1997).

This study demonstrates species differences in mast cell responses to adenosine; degranulation is mediated by A3Rs in rodents and by A2BRs in primates and canines.

185. van der Hoeven, D., Wan, T. C. \& Auchampach, J. A Activation of the $A_{3}$ adenosine receptor suppresses superoxide production and chemotaxis of mouse bon marrow neutrophils. Mol. Pharmacol. 74, 685-696 (2008).

186. Ramkumar, V., Stiles, G. L., Beaven, M. A. \& Ali, H. The A3 adenosine receptor is the unique adenosine receptor which facilitates release of allergic mediators in mast cells. J. Biol. Chem. 268, 16887-16890 (1993).

This study shows that degranulation of rat mast cells in mediated by A3R.

187. Sullivan G. W L Linden, J., Buster B L \& Scheld, W. M. Neutrophil A2A adenosine receptor inhibits inflammation in a rat model of meningitis: synergy with the type IV phosphodiesterase inhibitor, rolipram. J. Infect. Dis. 180, 1550-1560 (1999).

This study shows that PDE4 inhibition and A2AR activation synergistically inhibit oxidative burst in human neutrophils.

188. Mediero, A., Perez-Aso, M., Wilder, T. $\delta$

Cronstein, B. N. Methotrexate prevents wear particleinduced inflammatory osteolysis via activation of the adenosine A receptor. Arthritis Rheumatol. 67 849-555 (2014).

189. Kalvegren, H., Fridfeldt, J. \& Bengtsson, T. The role of plasma adenosine deaminase in chemoattractant- stimulated oxygen radical production in neutrophils. Eur. J. Cell Biol. 89, 462-467 (2010).

190. Sluyter, R., Barden, J. A. \& Wiley, J. S. Detection of P2X purinergic receptors on human B lymphocytes. Cell Tissue Res. 304, 231-236 (2001).

191. Pupovac, A., Geraghty, N. J., Watson, D. \& Sluyter, R. Activation of the $\mathrm{P} 2 \mathrm{X} 7$ receptor induces the rapid shedding of CD23 from human and murine B cells. Immunol. Cell Biol. 93, 77-85 (2015).

192. Bulanova, E. et al. ATP induces $\mathrm{P}_{2} \mathrm{X}_{7}$ receptorindependent cytokine and chemokine expression through $\mathrm{P}_{2} \mathrm{X}_{1}$ and $\mathrm{P}_{2} \mathrm{X}_{3}$ receptors in murine mast cells. J. Leukoc. Biol. 85, 692-702 (2009).

193. Cheng, R. D., Ren, J. J., Zhang, Y. Y. \& Ye, X. M. P2X4 receptors expressed on microglial cells in postischemic inflammation of brain ischemic injury. Neurochem. Int. 67, 9-13 (2014).

194. Wareham, K., Vial, C., Wykes, R. C., Bradding, P. \& Seward, E. P. Functional evidence for the expression of $\mathrm{P} 2 \mathrm{X} 1,2 \mathrm{X} 4$ and $\mathrm{P} 2 \mathrm{X} 7$ receptors in human lung mast cells. Br. J. Pharmacol. 157, 1215-1224 (2009)

195. Overes, I. M. et al. Expression of P2X5 in lymphoid malignancies results in LRH-1-specific cytotoxic T-cellmediated lysis. Br. J. Haematol. 141, 799-807 (2008).

196. Abramowski, P., Ogrodowczyk, C., Martin, R. \& Pongs, O. A truncation variant of the cation channel P2RX5 is upregulated during $T$ cell activation. PIOS ONE 9, e 104692 (2014).

197. Tsukimoto, M., Tokunaga, A., Harada, H. \& Kojima, S. Blockade of murine T cell activation by antagonists of P2Y6 and P2X7 receptors. Biochem. Biophys. Res. Commun. 384, 512-518 (2009).

198. Yu, Q. et al. Expression of $\mathrm{P} 2 \mathrm{X}_{6}$ receptors in the enteric nervous system of the rat gastrointestinal tract. Histochem. Cell Biol. 133, 177-188 (2010).

199. Xiang, Z. et al. Expression of P2X receptors on immune cells in the rat liver during postnatal development. Histochem. Cell Biol. 126, 453-463 (2006).
200. Pelegrin, P., Barroso-Gutierrez, C. \& Surprenant, A. $\mathrm{P} 2 \mathrm{X} 7$ receptor differentially couples to distinct release pathways for IL-1 $\beta$ in mouse macrophage. J. Immunol. 180, 7147-7157 (2008)

201. He, Y., Franchi, L. \& Nunez, G. TLR agonists stimulate Nlrp3-dependent IL-1 $\beta$ production independently of the purinergic $\mathrm{P} 2 \mathrm{X} 7$ receptor in dendritic cells and in vivo. J. Immunol. 190, 334-339 (2013).

202. Gicquel, T. et al. IL-1 $\beta$ production is dependent on the activation of purinergic receptors and NLRP3 pathway in human macrophages. FASEB J. 29, 4162-4173 (2015).

203. Nylander, S., Mattsson, C., Ramstrom, S. \& Lindahl, T. L. The relative importance of the ADP receptors, $P_{2} Y_{12}$ and $P_{2} Y_{1}$, in thrombin-induced platelet activation. Thromb. Res. 111, 65-73 (2003).

204. Li, H. Q. et al. P2Y4 receptor-mediated pinocytosis contributes to amyloid $\beta$-induced self-uptake by microglia. Mol. Cell. Biol. 33, 4282-4293 (2013).

205. Jin, J., Dasari, V. R., Sistare, F. D. \& Kunapuli, S. P. Distribution of P2Y receptor subtypes on haematopoietic cells. Br. J. Pharmacol. 123 , 789-794 (1998)

206. Kimura, T et al. Responses of macrophages to the danger signals released from necrotic cells. Int. Immunol. 26, 697-704 (2014).

207. Moreschi, I. et al. NAADP ${ }^{+}$is an agonist of the human $\mathrm{P} 2 \mathrm{Y}_{11}$ purinergic receptor. Cell Calcium 43, 344-355 (2008).

208. Wang, L. et al. ADP acting on $P 2 Y_{13}$ receptors is a negative feedback pathway for ATP release from human red blood cells. Circul. Res. 96, 189-196 (2005).

209. Dal Ben, D. et al. Purinergic P2X receptors: structural models and analysis of ligand-target interaction. Eur. J. Med. Chem. 89, 561-580 (2015).

Competing interests statement

The authors declare competing interests: see Web version for details. 